\title{
LA JUSTICIA CIVIL EN CRISIS. ESTUDIO EMPÍRICO EN LA CIUDAD DE SANTIAGO PARA APORTAR A UNA REFORMA JUDICIAL ORIENTADA HACIA EL ACCESO A LA JUSTICIA (FORMAL)
}

\author{
CIVIL JUSTICE IN CRISIS. EMPIRICAL RESEARCH IN THE CITY OF \\ SANTIAGO TO CONTRIBUTE TO A JUDICIAL REFORM TOWARDS \\ ACCESS TO (FORMAL) JUSTICE
}

\section{RICARDO LILLO*}

\begin{abstract}
RESUMEN: En el derecho comparado hay una percepción de crisis en la justicia civil. Esta sería tanto una de acceso como de relevancia. En base a estas críticas, que vienen a proveer de una nueva mirada a los estudios existentes en nuestro país, en este artículo se presentan los resultados de un estudio empírico en los tribunales civiles de Santiago, que da cuenta que desde este punto de vista la situación es aún peor de lo que se describe en nuestro medio. En base a sus hallazgos, se propone una reorientación del proceso de la reforma hacia el acceso a la justicia formal y en revalorizar su importancia para un Estado de Derecho.
\end{abstract}

Palabras clave: Acceso a la justicia, Justicia Civil, Reformas a la Justicia, Estudios Empíricos.

ABSTRACT: There is a perception of a crisis of the civil justice in the comparative law arena. This crisis would be one of access as one of relevance. From this critics, which provides a new insight to the existing studies in Chile, this article provides the findings of an empirical research over civil courts of Santiago, which shows, from this point of view, a state of affairs even worst from what is described in our legal community. From its findings, I propose a reorientation of the reform process focusing on access to formal justice and reassessing its value for the Rule of Law.

Key words: Access to justice, Civil courts, Judicial Reform, Empirical Legal Studies.

\section{INTRODUCCIÓN}

Hay una serie de estudios a nivel comparado donde se denuncia una profunda y generalizada crisis de la justicia civil ${ }^{1}$. Por una parte, esta crisis sería una de acceso. Es decir, habría una serie de individuos que no podrían llegar a la justicia civil para la satisfacción

LL.M. In Public Interest Law and Policy, University of California Los Angeles (UCLA). Profesor e investigador asociado, Facultad de Derecho UDP. Dirección postal: República 112, Santiago, Chile. Dirección electrónica: ricardo.lillo@mail.udp.cl.

Agradezco a las alumnas(os) del curso electivo "Introducción a la investigación empírica en el ámbito del derecho procesal", quienes colaboraron en el proceso de levantamiento de información: Carlos Donoso Pino, Cristina Molinos Moyano, Felipe Monsalves Gonzalez, Ignacio Fuentes Miranda, María José Escobar Taboada, Maximiliano Guiñez Escobar, Natalia Bustamante Rebolledo, Tomás Gómez Bruguera.

1 Principalmente a partir del estudio comparado de Adrian Zuckerman. Véase: ZuCKerman (1999). 
de sus pretensiones. Por la otra, esta crisis sería una de pérdida de relevancia. En base a esta última idea, incluso quienes poseen los medios para llegar y sostener un juicio civil lo estarían haciendo cada vez menos o, dicho de otra manera, esta no estaría siendo utilizada para cumplir los propósitos que debería. Esta literatura, que proviene del movimiento mundial por el acceso a la justicia, y que ha motivado reformas judiciales de gran relevancia a nivel comparado ${ }^{2}$, sirve de complemento a las críticas que en nuestro propio medio se han dirigido a la justicia civil chilena. En este sentido, ya en la década de los 90' se denunciaba que la justicia civil era discriminatoria respecto de ciertos grupos desaventajados y que había una serie de causas que no ingresaban al sistema de justicia ${ }^{3}$. Desde la doctrina procesal, el procedimiento civil chileno ha sido criticado por su excesiva escrituración, formalismo, y lenti$\operatorname{tud}^{4}$. Sin embargo, los estudios preexistentes no permiten realizar un diagnóstico acabado y a partir del cual construir fundamento que dé cuenta de la importancia de la justicia civil y que justifique la inversión en su reforma.

De esta manera, en este artículo se presentan los resultados de un estudio empírico realizado en la ciudad de Santiago, justamente con el objeto de aportar información e ideas al debate sobre la reforma de la justicia civil. A través de una muestra probabilística de expedientes obtenidos en los tribunales civiles pertenecientes a la jurisdicción de la Corte de Apelaciones de Santiago, doy cuenta de quienes son los principales usuarios de la justicia civil y para que fines la utilizan, al menos en esta jurisdicción. Los principales hallazgos, como se verá, permiten concluir que su funcionamiento es aún más deficitario de lo que ha descrito la literatura nacional.

A partir de dicho análisis, se proponen algunas reflexiones sobre por qué esta situación da cuenta de una crisis de nuestra justicia civil. Luego, el argumento principal que sostengo en este sentido es que la provisión de una justicia civil accesible es una obligación de los Estados en virtud del Derecho Internacional de los Derechos Humanos y a la vez un requerimiento central para el fortalecimiento del Estado de Derecho. Ambos argumentos justificarían una profunda reforma que mejore sus estándares de funcionamiento antes que su reemplazo por otras instancias alternativas, públicas o privadas.

Con estos fines, este artículo se divide de la siguiente manera. En primer lugar profundizo en esta percepción de crisis de la justicia. Se trata de información que busca poner en contexto al lector para describir el lugar desde donde se realizan están críticas. A continuación, y a partir de algunos estudios preexistentes, describiré la hipótesis que busqué probar respecto de los tribunales civiles pertenecientes a la jurisdicción de la Corte de Apelaciones de Santiago. En segundo lugar, se presentan los resultados de un estudio de carácter empírico y observacional donde se buscó determinar quienes son los litigantes y para qué usan los tribunales civiles de dicho territorio. Finalmente, y en base a lo anterior, respondo la pregunta de si efectivamente nuestra justicia civil se encuentra en crisis y en

\footnotetext{
2 Genn (2010) pp. 27-29.

3 Riego y Lillo (2015) pp. 12-17.

${ }^{4}$ Por ejemplo, en nuestro medio: Caroca (1997) pp. 16-20; Palomo (2005) pp. 173-174; Domínguez (2007) pp. 595-596.
} 
qué aspectos ello es así, para luego presentar algunos fundamentos de por qué me parece esencial reorientar la justicia civil chilena para que cumpla funciones diversas a la actuales.

\section{EL RELATO DE LA CRISIS DE LA JUSTICIA CIVIL}

El Código de Procedimiento Civil de 1902, aún con todas sus reformas ${ }^{5}$, utilizó como fuente fundamentalmente la Ley de Enjuiciamiento Civil Española de 1855. En otras palabras, siguió el antiguo modelo jerárquico del procedimiento europeo continental de origen romano-canónico e influenciado por las reformas post revolución francesa del siglo XIX 6 . En nuestro medio, Raúl Nuñez ha criticado al legislador de la época por no innovar en la materia siguiendo a esta fuente a pesar de que se trataba de un diseño que resultaba "ineficiente" y "añejo" en comparación con otras legislaciones procesales de la época".

En la década de los 90, en el contexto del proceso de la transición a la democracia ${ }^{8}$, se llevaron a cabo una serie estudios y encuestas que daban cuenta de los serios problemas de acceso a la justicia de algunos grupos de la población ${ }^{9}$, Entre otros factores, se mencionaba la necesidad de contar con los servicios de un abogado y el excesivo formalismo de la cultura judicial chilena, donde se incluyen cuestiones como el lenguaje y los rituales que no son comprensibles para las personas comunes, así como la larga duración de los procesos ${ }^{10}$,

Este último punto, la duración de los procesos, es de las críticas más frecuentes y antiguas hacia la justicia civil chilena. De hecho, para algunos, la duración y dilación innecesarias llegarían al punto de constituir una verdadera denegación de justicia ${ }^{11}$, Como decimos, este se trata de un tema recurrente en la doctrina y respecto del cual se han realizado algunos estudios de tipo empírico ${ }^{12}$.

Estas críticas a nivel nacional ya han sido documentadas ${ }^{13}$ y de cierta manera han sido reconocidas en los proyectos de reforma al procedimiento civil de los últimos años ${ }^{14}$. Todavía, es posible complementarlas con otras aristas que han sido identificadas principalmente en el ámbito comparado. Se trata de una serie de estudios donde se denuncia una crisis en la justicia civil a nivel mundial, tanto desde un punto de vista de acceso como de relevancia. Si bien no pretendo importar un discurso, en tanto en esta misma literatura se

\footnotetext{
5 Para una descripción de las diversas modificaciones, véase: OTERO (2000).

6 Para una descripción de este modelo en clave histórica, véase: DAMAšKA (1986) pp. 29-38; 206-212. En el mismo sentido: Couture (2014) pp. 18-20; Merryman y Pérez-Perdomo (2014) p. 190-210.

7 NuÑEZ (2005) pp. 175-189.

8 También existieron importantes iniciativas previas al retorno a la democracia. Para una descripción de ellas, véase: CERDA (1997) pp. 355-378.

9 Correa y Barros (1993); Barros (1997).

10 Correa y Jiménez (1997) p. 79.

11 Domínguez (2007) pp. 595-596.

12 Sobre los estudios de duración que se realizaron en esa época, véase: RiEgo y LiLlo (2015) pp. 18-21.

13 Véase: Riego y Lillo (2015), pp. 9-54.

14 Véase: Mensaje presidencial, No 398-357, 18 de mayo de 2009. Disponible en https://www.camara.cl/pley/ pley_detalle.aspx?prmID=6958\&prmBoletin=6567-07 Fecha de consulta: 28 de agosto de 2018; MinISTERIO DE Justicia (2012) pp. 13-16.
} 
critica el diagnóstico en base a los cuales se ha ido construyendo este relato ${ }^{15}$, este resulta útil para construir una versión propia de la crisis en la que se encuentra nuestro país.

Con estos fines, en este primer capítulo describiré esta percepción a nivel comparado, y luego daré cuenta de algunos de los estudios nacionales que permitirían describir el estado de la cuestión en nuestro país. A partir de lo anterior, formularé la hipótesis que pretendo validar empíricamente, si no respecto de todo nuestro país, si al menos para la jurisdicción de la Corte de Apelaciones de Santiago.

\subsection{LA CRISIS A NIVEL COMPARADO Y ANTECEDENTES NACIONALES SOBRE EL ESTADO DE} LA JUSTICIA CIVIL

Adrian Zuckerman, cerrando el siglo XX, concluyó a partir de una serie de estudios nacionales que la justicia civil, tanto en países del Common Law como de la tradición del derecho continental, se encontraría en un estado de crisis. Esta crisis sería, por una parte, una de acceso en tanto amplios grupos de la población no contarían con las condiciones adecuadas para satisfacer sus necesidades legales de manera efectiva. Por la otra, sería una de pérdida de relevancia. Es decir, que inclusive aquellos que podrían acceder estarían cada vez usando menos el proceso judicial como mecanismo de resolución de conflictos. De manera más reciente, Genn señala que en diversos países se ha ido adoptando una retórica común del diagnóstico, de jurisdicción en jurisdicción, de cultura legal a cultura legal ${ }^{16}$.

Más allá de las particularidades que es posible observar en el estudio comparado de Zuckerman, es posible observar factores y tendencias comunes ${ }^{17}$. Por una parte, entre los países anglosajones evaluados el principal problema desde el punto de vista del acceso serían los altos costos de litigar ante los tribunales civiles y la consiguiente insuficiencia de los servicios de asistencia legal que ello trae aparejado ${ }^{18}$. De esta manera, se suele criticar el procedimiento de Discovery en Estados Unidos donde, para que las partes puedan recopilar y acceder los antecedentes de hecho necesarios para afrontar el juicio, es necesario contar con importantes recursos económicos para que resulte efectivo ${ }^{19}$. Por otro lado, en aquellos que pertenecen a la tradición del derecho continental como Francia, Italia, Portugal, y España, la principal crítica se dirige a la larga duración de los procedimientos civiles, llenos de ritualidades y formalismos que terminan por hacerlos inútiles para los eventuales litigantes ${ }^{20}$.

Para Cappelletti y Garth han sido los propios tribunales, cruciales en la expansión y reconocimiento de derechos fundamentales, quienes paradójicamente han generado un escenario complejo para hacerlos efectivos. El problema sería que sus propias características

\footnotetext{
15 Genn (2010) pp. 27-29.

16 Genn (2010) pp. 27-29.

17 ZuCKERMAN (1999) pp. 42-51.

18 En el caso de Inglaterra, estos problemas motivaron un profundo proceso de reforma. A este respecto, véase: Michalik (1999) pp. 156-157. Sin embargo, estas no han cumplido los objetivos propuestos y han sido criticadas por no ser lo suficientemente radicales. Véase: ZANDER (1995) pp. 79-96. En Canadá, véase: TreBILCOCK et al. (2012), pp. 3-4. En Estados Unidos, véase: Weinstein (2016) pp. 3-20; Rhode (2004), pp. 3-13; Croley (2017) pp. 117

19 Zuckerman (1999) pp. 19-21. Ver también: Kagan (2003) pp. 108-109

20 ZuCKERMAN (1999) pp. 13-14.
} 
los haría una alternativa poco atractiva para el común de la gente, sobre todo respecto de asuntos de menor complejidad, pero de alta prevalencia en la población ${ }^{21}$. En estos, si los procedimientos judiciales operan de manera ineficiente, costosa, y lenta, aun cuando un derecho subjetivo sea finalmente vindicado este tendrá menor significancia para el ganador. En este sentido, estas ineficiencias desalentarían a los potenciales litigantes de llevar sus demandas a tribunales ${ }^{22}$.

Para Raz es el propio modelo burocrático del Estado de Derecho el que tiende a crear un abismo entre el derecho y las personas. Este autor señala que el énfasis en procedimientos meticulosos y complejos hace que sea necesario contar con los servicios profesionales de individuos altamente capacitados pero costosos. De esta manera, los temas jurídicos terminan formulándose en términos técnicos y en general en un lenguaje muy distante a las personas comunes ${ }^{23}$.

Desde el punto de vista de la crisis de relevancia, Genn destaca que datos tanto de Estados Unidos como de Inglaterra mostrarían que cada vez se usarían menos los tribunales civiles. Para esta autora, y siguiendo a Galanter, el declive en el ingreso de causas habría seguido luego una época de expansión de derechos durante el Estado de Bienestar ${ }^{24}$. Esta expansión trajo consigo un aumento sostenido en los niveles de litigación, y consecuentemente a lo que Galanter describió como la apropiación de esos nuevos mercados por parte de litigantes que tendieron a abusar de estos espacios. Finalmente, ello habría terminado por incentivar políticas destinadas a extraer asuntos de la justicia civil hacia otros mecanismos privados de solución de controversias ${ }^{25}$.

En Chile, hay estudios que dan cuenta que la situación de nuestra justicia civil, con sus particularidades, parece hacer eco con la denuncia realizada a nivel comparado desde la perspectiva de acceso. En cuanto a los costos, por ejemplo, si bien no contamos con estudios y datos que permitan estimar adecuadamente el valor de litigar, encuestas de los 90 dan cuenta de una opinión negativa de la población en este sentido, por ejemplo, por el alto valor que implica contratar un abogado ${ }^{26}$. Se trata este punto de una deficiencia en el diagnóstico y una futura línea de investigación a explorar ${ }^{27}$. En cuanto a la duración, el formalismo, así como respecto a otros factores propios del procedimiento como barreras de acceso, como he mencionado con anterioridad, hay varios estudios que apuntan hacia la misma línea ${ }^{28}$.

Los principales estudios realizados en Chile son de carácter cualitativo y principalmente han tratado de dar cuenta de la percepción que tendrían ciertos sectores de la sociedad respecto de la justicia civil. De esta manera, las investigaciones de Correa y Barros en

\footnotetext{
21 Cappelletti y Garth (1996) p. 59.

22 AtTiyah y Summers (1987) p. 195.

23 RAZ (1995) pp. 372-373.

24 Genn (2010) pp. 30-31; Galanter (2006) p. 19

25 Genn (2010) pp. 31-32. Galanter (2006) p. 21.

26 Correa y Barros (1993) p. 45; Barros (1997) p. 19. Desde un punto de vista teórico: Marinoni (2010) pp. 186-188.

27 Riego y Lillo (2015), p. 48.

28 Para un análisis de estas críticas, véase: Riego y Lillo (2015), pp. 9-54.
} 
los 90 muestran que la opinión de las personas encuestadas era mayoritariamente negativa, fundamentalmente por la lentitud, la ineficiencia y el carácter discriminatorio de la justicia en contra de los pobres ${ }^{29}$.

Datos recientes del Programa de Naciones Unidas para el Desarrollo (PNUD) muestran también un deterioro en la confianza hacia los tribunales de justicia (gráfico 1$)^{30}$. Similar tendencia es posible observar en base a los datos del Latinobarómetro si se consideran aquellos que declaraban tener "algo" o "mucha" confianza ${ }^{31}$.

\section{GRÁFICO 1}

Confianza en Tribunales de Justicia o Poder Judicial según datos del PNUD y Latinobarómetro (2008-2016)

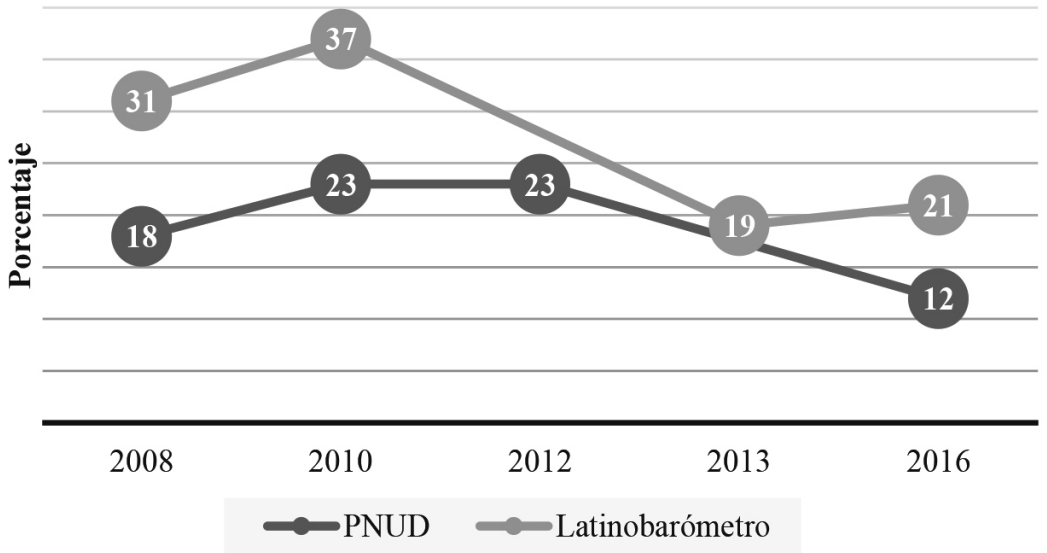

Los estudios de los 90 también dan cuenta que desde esa época hay una serie de conflictos relacionados al ámbito civil de alta prevalencia entre los encuestados ${ }^{32}$. De manera más reciente, el Ministerio de Justicia elaboró una Encuesta Nacional de Necesidades Jurídicas y Acceso a Justicia, donde se destaca que al menos 4 de cada 10 personas en Chile tuvo alguna necesidad legal en el período cubierto y que pudieron haber requerido información legal, asesoría jurídica o representación judicial ${ }^{33}$. Fuera del ámbito penal, que ocupó un 34,6\% del total de necesidades legales declaradas por los encuestados ${ }^{34}$, las principales necesidades jurídicas en materia civil se dan en temas de vivienda (22,5\%), econo-

29 Correa y Barros (1993) p. 23; Barros (1997) p. 19.

30 Los datos del PNUD representan aquellos encuestados que tienen "mucha" o "bastante" confianza en los Tribunales de Justicia. Véase: PNUD (2016): “Auditoría a la Democracia, Más y Mejor Democracia para un Chile Inclusivo, IV Encuesta Nacional”. Disponible en: http://www.cl.undp.org/content/chile/es/home/presscenter/ pressreleases/2016/09/09/pnud-presenta-iv-encuesta-auditor-a-a-la-democracia.html Fecha de consulta: 3 de Agosto de 2018.

31 Los datos del Latinobarómetro representan aquellos encuestados que tienen "algo" o "mucha” confianza en el Poder Judicial. Información disponible en: http://www.latinobarometro.org/latOnline.jsp Fecha de consulta: 3 de Agosto de 2018.

32 Correa y Barros (1993) p. 73; Vanderschueren y Oviedo (1995) pp. 140, 141; Barros (1997) p. 30.

33 Ministerio de Justicia (2015) p. 27.

34 Ministerio de Justicia (2015) p. 30. 
mía y patrimonio $(20 \%)$ y salud $(18,9 \%)$. Le siguen los problemas sobre temas de trabajo $(17,9 \%)$, familia (14\%), discriminación y vulneración de derechos $(12,8 \%)$, seguros de salud $(11,8 \%)$ y educación $(8,1 \%)^{35}$.

\subsection{Formulación de UNA HiPÓtesis. QuiÉN USA Y PARA QUÉ USAN LA JUSTICIA CIVIL}

Desde el punto de vista de la crisis de relevancia, la mayor crítica que es posible observar en la literatura nacional es que la labor judicial se destina principalmente a materias de orden comercial con un bajo componente jurisdiccional ${ }^{36}$. De esta manera, el tipo de caso que compone gran parte del ingreso civil serían causas ejecutivas o de cobranza, donde la función que realizarían los jueces sería de tipo administrativo o notarial ${ }^{37}$. Así lo demostrarían estudios realizados en los $90^{\prime}$ como otros más recientes ${ }^{38}$. En relación a este último punto, un estudio elaborado por el Centro de Estudios de Justicia de las Américas (CEJA) daba cuenta que en el año 2009 del total del ingreso de causas civiles la gran mayoría de ellas correspondió a juicios ejecutivos $(70,55 \%)$, y el resto a gestiones preparatorias de la vía ejecutiva $(25,89 \% \text {. })^{39}$.

Los últimos datos disponibles muestran que esta realidad se mantiene, al menos en la jurisdicción de la Corte de Apelaciones de Santiago. Así, datos obtenidos por parte del Poder Judicial ${ }^{40}$ muestran que del total de ingresos civiles entre los años 2014 y 2016 (2.827.658), el $92 \%$ de causas eran juicios ejecutivos o gestiones preparatorias de la vía ejecutiva, muchas de las cuales a partir del 2011 son tramitadas masivamente sin importar mayor carga de trabajo para los jueces civiles (gráfico 2$)^{41}$.

35 Por supuesto, un mismo individuo podía declarar más de una necesidad legal insatisfecha y en diversas materias. Ministerio de Justicia (2015) p. 30.

36 Vanderschueren y Oviedo (1995) p. 139.

37 VARgas et al. (2001) p. 92. De manera más reciente: García y Leturia (2006) p. 353; VARgas (2011) p. 479.

38 De acuerdo a un estudio realizado por Juan Enrique Vargas, Carlos Peña y Jorge Correa Sutil, entre el período 1977-1995, el promedio de cobranzas judiciales en Santiago alcanzaba el 61\% del total de las causas contenciosas ingresadas en sede civil. Correa et al. (1999) p. 10. De acuerdo a José Francisco García y Francisco Leturia el promedio respecto al total de los ingresos para el período entre 1995 y 2003 también era de $61 \%$ de cobranzas. García y Leturia (2006) p. 353. Otro estudio más reciente del año 2012, daba cuenta de que 4 de las 5 materias ingresadas a nivel nacional se trataban de causas tramitadas bajo el procedimiento ejecutivo o eran gestiones preparatorias de la vía ejecutiva. De hecho, estas 4 materias ocupaban el 77,8\% del ingreso en este período. EMG CONSUltores (2012) p. 32

39 Centro de Estudios de Justicia de las Américas (2011) p. 15.

40 Información recibida con fecha 29 de marzo de 2017, Oficio № 1859-2017, Corporación Administrativa del Poder Judicial. En poder del autor.

41 Véase: Acta 34-2011, Auto Acordado que complementa la instrucción contenida en el Acta 27-2009, sobre aplicación del artículo segundo de la ley 18.120 a los procedimientos ejecutivos y regula los procedimientos administrativos asociados a las causas denominadas como "masivas". 


\section{GRÁFICO 2}

Ingresos civiles por tipo de procedimiento (2014-2016)

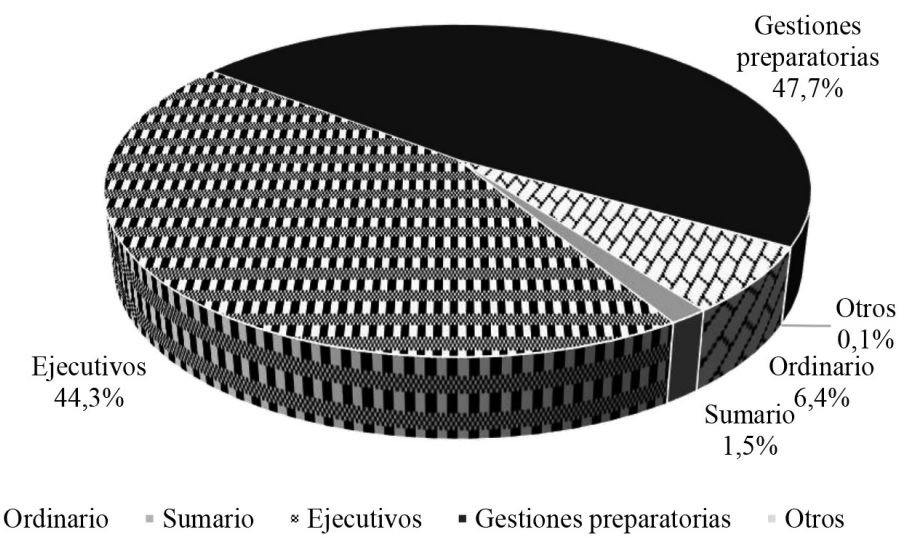

Fuente: Elaboración propia en base a datos provistos por la Unidad de Estadística e Informática del Poder Judicial.

El procedimiento sumario, diseñado para brindar una solución rápida en aquellos casos en que ello resulte necesario para que la pretensión sea eficaz, además de los asuntos expresamente contemplados en la regulación procesal ${ }^{42}$, ocupaba tan solo un $1,5 \%$ del total de causas entre los años 2014-2016 (gráfico 2).

El procedimiento ordinario, en sus diversas versiones (mínima, menor, y mayor cuantía), tiene una prevalencia menor dentro del tipo de ingresos en tribunales civiles (6,4\%). A mayor abundamiento, de los 181.044 casos ingresados entre los años 2014 y 2016 en este procedimiento, un 68\% eran causas de cobros de pesos. Otros asuntos de tanta relevancia desde el punto del derecho civil sustantivo no superan el 5\% (gráfico 3).

\section{GRÁFICO 3}

Ingresos civiles en procedimiento ordinario por materia (2014-2016)

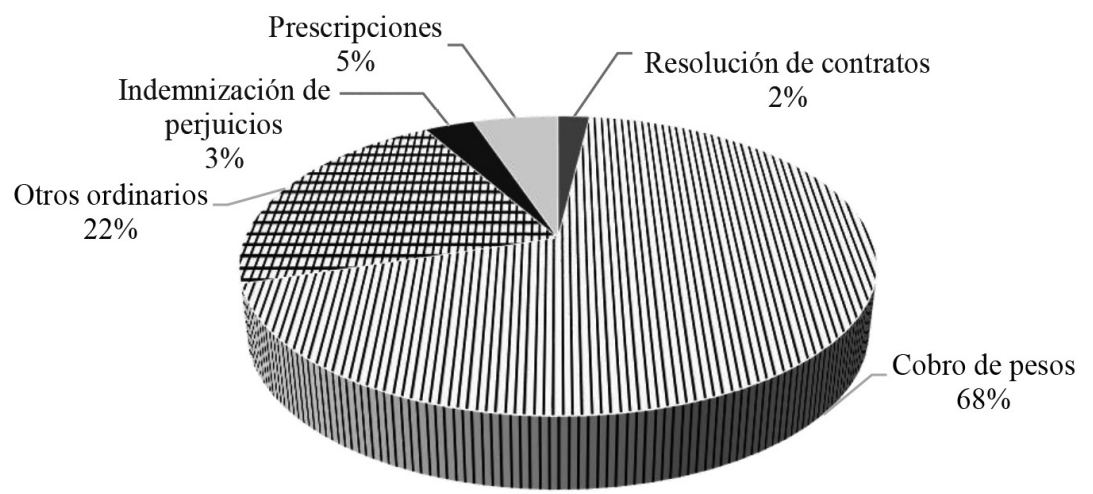

Fuente: Elaboración propia en base a datos provistos por la Unidad de Estadística e Informática del Poder Judicial.

42 Véase: Código de Procedimiento Civil, Art. 680. 
El problema no es solo la alta homogeneidad del ingreso sino que, y a partir de estos estudios y datos preexistentes, es posible construir una hipótesis en el sentido de que quiénes los usarían son primordialmente personas jurídicas y dentro de este grupo, grandes empre$\operatorname{sas}^{43}$. En base a datos del 2009, el CEJA describía que tanto en el procedimiento ordinario, como en el ejecutivo, los principales demandantes serían personas jurídicas y los demandados personas naturales ${ }^{44}$. Por otro lado, se señalaba que en el procedimiento sumario, tanto respecto de los demandantes como de los demandados se trataría en su mayoría de personas naturales ${ }^{45}$. Es esta la hipótesis que he pretendido validar y profundizar a partir de una muestra de causas ingresadas en los tribunales del ramo de la jurisdicción de la Corte de Apelaciones de Santiago, de cuyos resultados doy cuenta en lo que sigue de este trabajo.

\section{RESULTADO DEL ESTUDIO EMPÍRICO EN LA JURISDICCIÓN DE LA CORTE DE APELACIONES DE SANTIAGO}

El estudio se trata de una investigación empírica de carácter observacional, realizado en base a una muestra aleatoria de causas civiles ingresadas entre los años 2014 a 2016, que como se señalara antes alcanzaba un total de 2.827.658. A partir de la información proporcionada por el propio sistema de gestión del Poder Judicial de donde se obtuvo la muestra, se dividieron las causas en 4 grupos según el tipo de procedimiento: i) ejecutivo, gestiones preparatorias, y medidas prejudiciales (en adelante me referiré a estos simplemente como procedimientos ejecutivos), ii) ordinario, iii) sumario, y iv) concursal y quiebras (o simplemente concursales). De esta manera, se obtuvo una muestra de 1.000 causas distribuidas de la siguiente manera ${ }^{46}$ :

TABLA 1

Muestra aleatoria en base a ingresos civiles Corte de Apelaciones de Santiago (2014-2016)

\begin{tabular}{lc}
\hline \multicolumn{1}{c}{ Tipo de procedimiento } & Cantidad de causas \\
\hline Ejecutivo, gestiones preparatorias, y medidas prejudiciales & 264 \\
Ordinario & 260 \\
Sumario & 239 \\
Concursal y Quiebras & 237 \\
\hline Total & 1.000 \\
\hline
\end{tabular}

43 Un estudio con datos de 1996 del 6o Juzgado Civil de Santiago mostraban que el 36\% de los demandantes eran bancos e instituciones financieras, $10,3 \%$ eran casas comerciales, el 36,2\% otras sociedades y las personas naturales no representaban más que el 17,4\% del total. Véase: CorreA et al. (1999) p. 91.

44 Lamentablemente no se entregan datos de proporciones obtenidos en dicho estudio. CENTRO DE EsTUDIOS de Justicia de las Américas (2011) pp. 63, 67.

45 Centro de Estudios de Justicia de las Américas (2011) pp. 65-66.

46 Las diferencias se produjeron porque hubo algunas excluidas del listado inicial, sea porque no fue posible extraer información desde la página web del Poder Judicial o porque se encontraban repetidas luego de un proceso de muestreo consecutivo. Se sobre representaron algunos procedimientos dentro de la muestra ya que el objetivo era obtener resultados estadísticamente relevantes dentro de cada uno. 
En cuanto a las materias discutidas en cada uno de estos procedimientos, es posible observar una alta correlación entre aquellas que ocupan los principales ingresos en la muestra versus la población completa. Así, respecto del procedimiento ejecutivo las principales materias eran la citación a confesión de deudas $(47,7 \%$ en la muestra y $49 \%$ en la población) y cobro de pagarés (42,8\% en la muestra y $41,7 \%$ en la población). Como dijimos con anterioridad, en el procedimiento ordinario la principal materia es cobro de pesos (73,5\% en la muestra frente a un $68,3 \%$ en la población). Por su parte, en el procedimiento sumario, la principal materia está relacionada con la terminación inmediata del arriendo por no pago de rentas (34,3\% en la muestra y 32,8\% en la población). Finalmente, entre los procedimientos concursales y de quiebra, la mayor parte de las causas eran liquidaciones voluntarias de deudas, tanto respecto de personas naturales $(40,5 \%$ en la muestra versus un $41,3 \%$ en la población), como de empresas deudoras $(27,4 \%$ en la muestra y $28,9 \%$ en la población).

\subsection{QUIENES ERAN LOS DEMANDANTES}

Un primer aspecto a analizar respecto a la hipótesis antes descrita, es determinar el tipo de personalidad (natural o jurídica de derecho privado o público) de los demandantes. En este sentido, tanto en el procedimiento ejecutivo como en el procedimiento ordinario, gran parte de los demandantes eran personas jurídicas de derecho privado, en ambos casos en proporciones que superan el $90 \%$. Por el contrario, en el procedimiento sumario, así como en el procedimiento concursal y de quiebras, los demandantes son mayormente personas naturales, mientras que las personas jurídicas de derecho privado ocupaban un 38\% y $37 \%$ respectivamente. Finalmente, respecto de este punto, destaca la baja prevalencia de demandantes personas jurídicas de derecho público, que obtiene porcentajes menores a un $3 \%$ en cada uno de los procedimientos (gráfico 4).

\section{GRÁFICO 4}

Tipo de demandante según procedimiento (2014-2016)

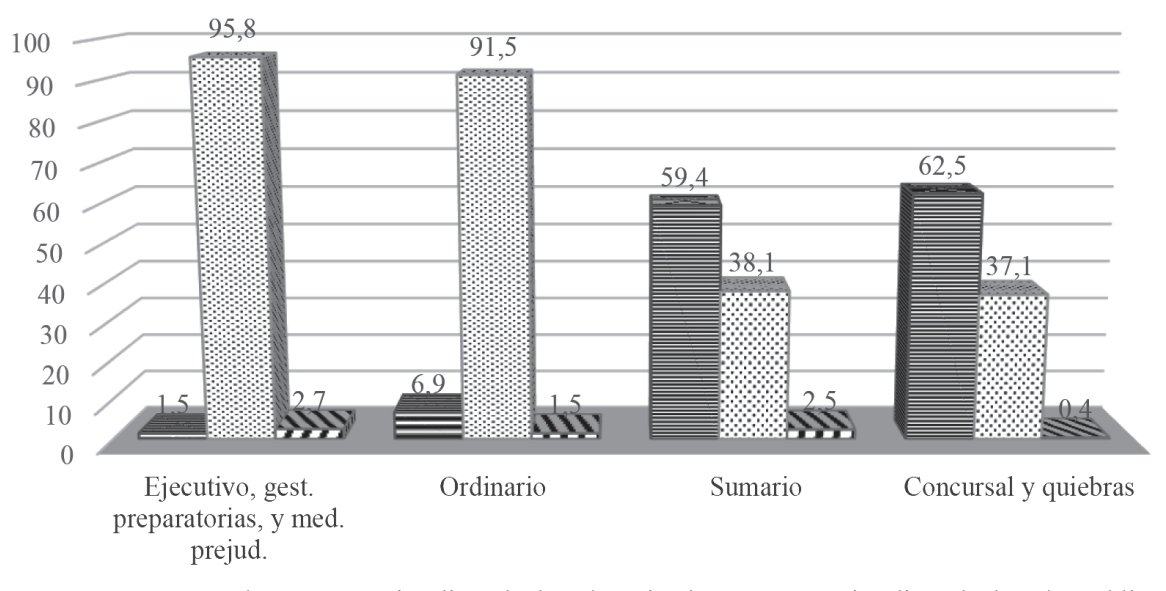

曰Persona natural $₫$ Personas jurídicas de derecho privado $\mathbf{\Delta P e r s o n a s ~ j u r i ́ d i c a s ~ d e ~ d e r e c h o ~ p u ́ b l i c o ~}$ 
En aquellos casos donde el demandante era una persona jurídica de derecho privado, que como ya veíamos en la gran mayoría en el procedimiento ejecutivo y ordinario, gran parte de ellas se trataban de sociedades civiles y/o comerciales. Ello ocurre incluso en aquellos procedimientos donde los demandantes no eran mayoritariamente personas jurídicas (tabla 2).

TABLA 2

Tipo de personalidad jurídica demandantes según procedimiento

\begin{tabular}{lcccc}
\hline \multirow{2}{*}{$\begin{array}{l}\text { Tipo de personalidad jurídica de derecho } \\
\text { privado }\end{array}$} & $\begin{array}{c}\text { Tipo de procedimiento } \\
\text { Ejecutivo } \\
(\%)\end{array}$ & $\begin{array}{c}\text { Ordinario } \\
(\%)\end{array}$ & Sumario $(\%)$ & $\begin{array}{c}\text { Concursal } \\
(\%)\end{array}$ \\
\cline { 2 - 5 } Corporación sin fines de lucro & $7(2,8)$ & $9(3,8)$ & $6(6,6)$ & $1(1,1)$ \\
Fundación & 0 & 0 & $3(3,3)$ & $1(1,1)$ \\
Sociedades civiles y/o comerciales & $246(97,2)$ & $229(96,2)$ & $82(90,1)$ & $86(97,7)$ \\
\hline $\begin{array}{l}\text { Total } \\
\text { Fisher's exact } P=0,010\end{array}$ & $253(100)$ & $238(100)$ & $91(100)$ & $88(100)$ \\
\hline
\end{tabular}

Ya en este punto podemos testear la principal tesis proveniente de antiguos estudios respecto a que el principal usuario activo (demandante) de la justicia civil en nuestro país serían empresas. De esta manera, si consideramos como hipótesis nula que en estos procedimientos la probabilidad de que el demandante sea una empresa u otro tipo de personalidad (jurídica o natural) es la misma, esta puede ser descartada a un alto nivel de significancia estadística. De esta manera, bajo un estándar de 95\% de confianza, podemos señalar con alta significancia estadística que la proporción de personas empresas en el procedimiento ejecutivo se encuentra entre un $90 \%$ y un $96 \%$, y en el procedimiento ordinario entre un $84 \%$ y un $92 \%$. Por otro lado, se confirma también la hipótesis extraída del estudio de CEJA sobre que en el procedimiento sumario la mayoría de demandantes son personas naturales, ya que el intervalo de confianza para el porcentaje de empresas en este caso se encuentra entre $28 \%$ y $40 \%$, es decir, en cualquier caso, presentaría una proporción menor. De manera similar, es posible afirmar que las empresas representan entre un 30\% y un 42\% de los demandantes en los procedimientos concursales y de quiebra (Tabla 3). 
TABLA 3

Demandantes empresas según procedimiento

\begin{tabular}{|c|c|c|c|c|}
\hline $\begin{array}{l}\text { Demandante } \\
\text { es empresa }\end{array}$ & $\begin{array}{c}\text { Ejecutivo, G. } \\
\text { Preparatorias, y M. } \\
\text { Prejudiciales (\%) }\end{array}$ & Ordinario (\%) & Sumario $(\%)$ & $\begin{array}{l}\text { Concursal y } \\
\text { Quiebras (\%) }\end{array}$ \\
\hline No & 6,8 & 11,9 & 65,7 & 63,7 \\
\hline $\mathrm{Si}$ & $93,2 *$ & $88,1^{*}$ & $34,3^{*}$ & $36,3^{*}$ \\
\hline $\begin{array}{c}\text { Total } \\
\text { Test Chi } \\
P=0,000 \\
\end{array}$ & 100 & 100 & 100 & 100 \\
\hline $\begin{array}{c}*(I C \text { de } 95 \%) \\
\text { Z-Test } \\
\text { (proporción) }\end{array}$ & $\begin{array}{c}.9014131-.9622233 \\
P=0,000\end{array}$ & $\begin{array}{c}.8413792-.9201593 \\
P=0,000\end{array}$ & $\begin{array}{c}.2829085-.403284 \\
P=0,000\end{array}$ & $\begin{array}{c}.3016534-.424085 \\
P=0,000\end{array}$ \\
\hline
\end{tabular}

No obstante, el objetivo de este trabajo no es solo confirmar o rechazar esta hipótesis general sobre si los demandantes en nuestra justicia civil son en su mayoría empresas o personas naturales. Más allá de lo anterior, y tras confirmar estas proposiciones, he pretendido profundizar caracterizando de mejor manera quienes son los demandantes. Ahora, para tener una idea del tipo de sociedad civil y comercial que representaba el principal usuario de la justicia civil en esta muestra he seguido una serie de factores.

En primer lugar, se ha codificado a las sociedades civiles y/o comerciales según su personalidad jurídica en particular. Así, las he clasificado según si se encontraban constituidas como Sociedades Anónimas ${ }^{47}$, Empresas Individuales de Responsabilidad Limitada, Sociedades de Responsabilidad Limitada, Sociedades Por Acciones, y he agrupado a las restantes en una categoría de "otros".

En relación al tipo de sociedades bajo las cuales se constituían los demandantes, gran parte de ellas se trataban de sociedades anónimas. Ello es particularmente cierto respecto de los procedimientos ejecutivos y ordinarios, donde ya sabíamos los demandantes son mayoritariamente empresas. Luego, llama la atención la categoría "otros" que ocupa un 19\% en el caso del procedimiento ejecutivo. De la revisión pormenorizada de estos casos, se pudo observar que estos demandantes tenían una denominación de "fondos de inversión privados", esto es, de un patrimonio de afectación integrado por aportes realizados por personas o entidades, administrados por Administradoras Generales de Fondos o por sociedades anónimas cerradas, por cuenta y riesgo de sus aportantes y que no hacen oferta pública de sus valores ${ }^{48}$. Tan solo en los procedimientos sumarios y concursales se observa en una mayor dispersión en términos del tipo de sociedades que aparecían como demandantes. De esta manera, el 26\% eran empresas de responsabilidad limitada en el procedimiento suma-

\footnotetext{
47 Abiertas y cerradas.

48 Estos se rigen exclusivamente por sus reglamentos internos, por las normas del Capítulo V de la Ley No 20.712 sobre Administración de Fondos de Terceros y Carteras Individuales, y el Capítulo IV de su Reglamento, el DS No 129, de Hacienda. Disponible en: http://www.svs.cl/educa/600/w3-propertyvalue-987.html Fecha de consulta: 23 de julio de 2018.
} 
rio, mientras que un $35 \%$ lo eran en los procedimientos concursales. En estos últimos, además, las sociedades por acciones representaban un 13\% (tabla 4).

TABLA 4

Casos con demandantes Sociedades Civiles y Comerciales según tipo de personalidad jurídica y procedimiento

\begin{tabular}{lcccc}
\hline $\begin{array}{c}\text { Tipo de Sociedad } \\
\text { Civil y/o Comercial }\end{array}$ & $\begin{array}{c}\text { Ejecutivo, G. Preparatorias, } \\
\text { M. Prejudiciales }(\%)\end{array}$ & $\begin{array}{c}\text { Ordinario } \\
(\%)\end{array}$ & Sumario (\%) & $\begin{array}{c}\text { Concursal } \\
\text { y Quiebras } \\
(\%)\end{array}$ \\
\hline SA & 80,1 & 88,6 & 70,7 & 48,8 \\
EIRL & 0 & 0,9 & 1,2 & 2,3 \\
LTDA & 0,8 & 3,5 & 25,6 & 34,8 \\
SPA & 0 & 6,6 & 0 & 12,8 \\
Otro & 19,1 & 0,4 & 2,4 & 1,2 \\
\hline Total & 100 & 100 & 100 & 100 \\
Test $\mathrm{Chi}^{2} P=0,000$ & & & & \\
\hline
\end{tabular}

Un segundo criterio para caracterizar al demandante en estos procedimientos fue intentar determinar el tamaño de las empresas. Para ello, se utilizó como equivalente el registro PRO-PYME del Servicio de Impuestos Internos (SII) donde los contribuyentes pueden identificarse como tales. En concordancia con la anterior variable, es posible concluir que las empresas que eran demandantes, tanto en el procedimiento ejecutivo como en el ordinario, se trata no solo de sociedades anónimas, sino que, además, de grandes empresas. Así, los contribuyentes no se encontraban en el citado registro del SII en el $93 \%$ y $94 \%$ respectivamente. Por el contrario, y probablemente porque el tipo de sociedades era más diverso, es posible observar una mayor participación de pequeñas y medianas empresas en el procedimiento sumario $(40 \%)$ y sobre todo en los procedimientos concursales, donde son la mayoría (64\%) (gráfico 5). 


\section{GRÁFICO 5}

Sociedades civiles y/o comerciales en el registro PRO-PYME del SII

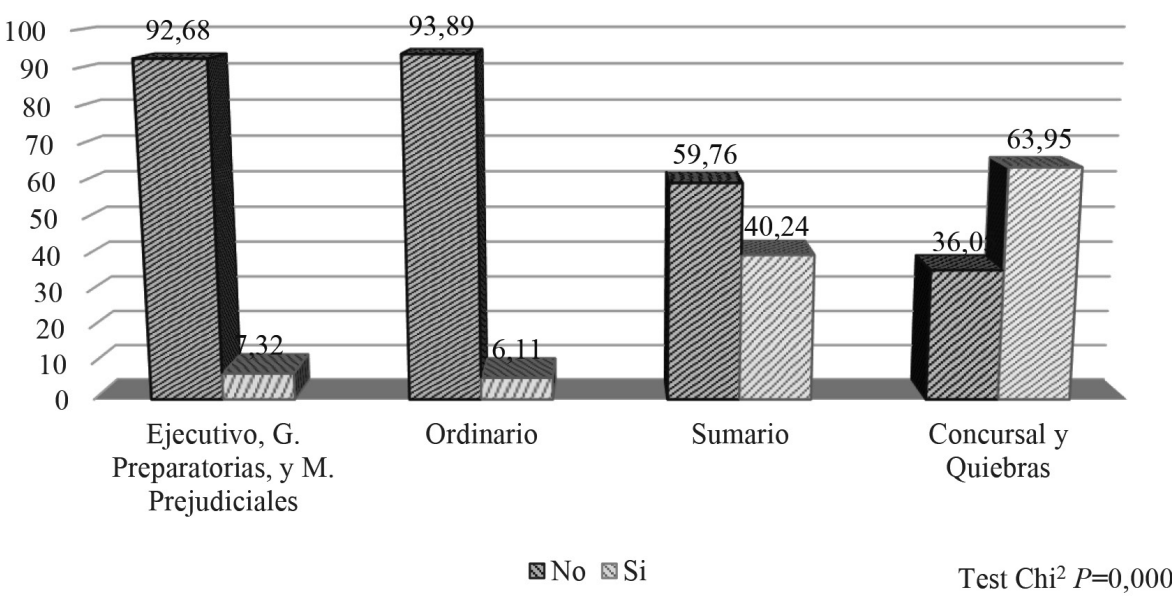

Este último punto no necesariamente implica buenas noticias. Por el contrario, pareciera que mientras grandes empresas son demandantes en los procedimientos de mayor prevalencia, y en menor medida en el procedimiento sumario, en los procedimientos concursales y de quiebra se trataría de pequeñas y medianas solicitando procedimientos de liquidación de deudas. Luego volveré sobre este punto.

La tercera aproximación realizada para comprender un poco mejor de qué tipo de empresas son las que usan el sistema de justicia civil, fue consultar las bases de datos del SII para ver las actividades registradas por los demandantes. De esta manera, gran parte de las sociedades civiles y/o comerciales que eran demandantes en el procedimiento ejecutivo pertenecían al rubro de los bancos y financieras, o estaban registradas como administradoras de fondos de inversión. De hecho, si se agrupan siguiendo la clasificación del SII de actividades económica, el $76 \%$ de los demandantes tenían como principal rubro la intermediación financiera (gráfico 6). 


\section{GRÁFICO 6}

Actividades demandantes en procedimiento ejecutivo según registro SII

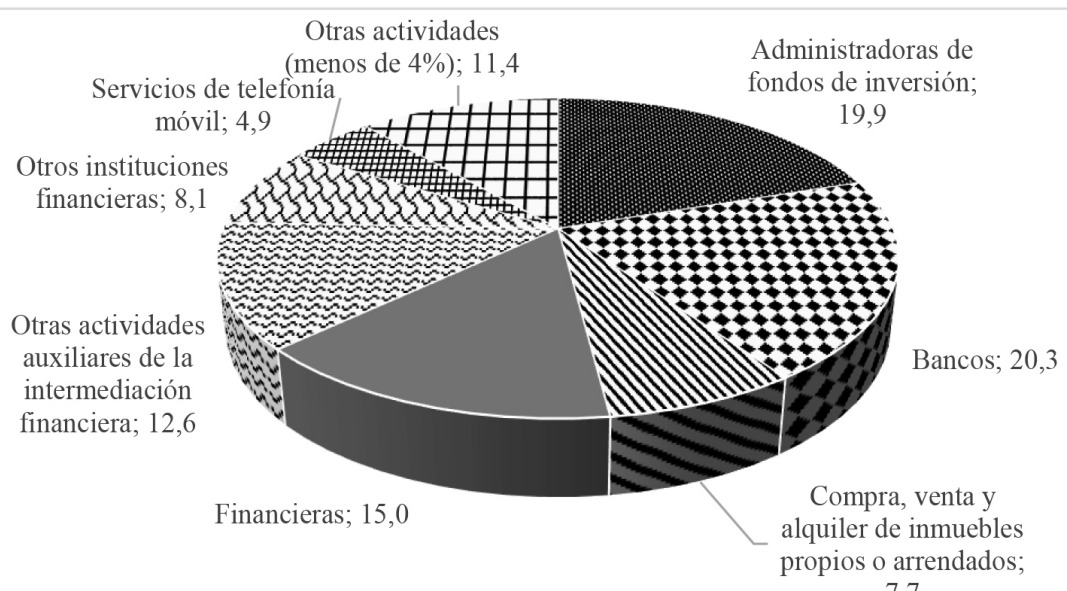

En el caso del procedimiento ordinario, los demandantes tenían registrada como actividad principal el rubro de la intermediación financiera en un 48,7\%. Luego, y siguiendo en orden de importancia, aquellas relacionadas a la compra, venta y alquiler de inmuebles propios o arrendados (inmobiliarias) alcanzaban un 16,4\%. Llama también la existencia de institutos profesionales $(7,5 \%)$ en calidad de demandantes (gráfico 7 ).

\section{GRÁFICO 7}

Actividades demandantes en procedimiento ordinario según registro SII

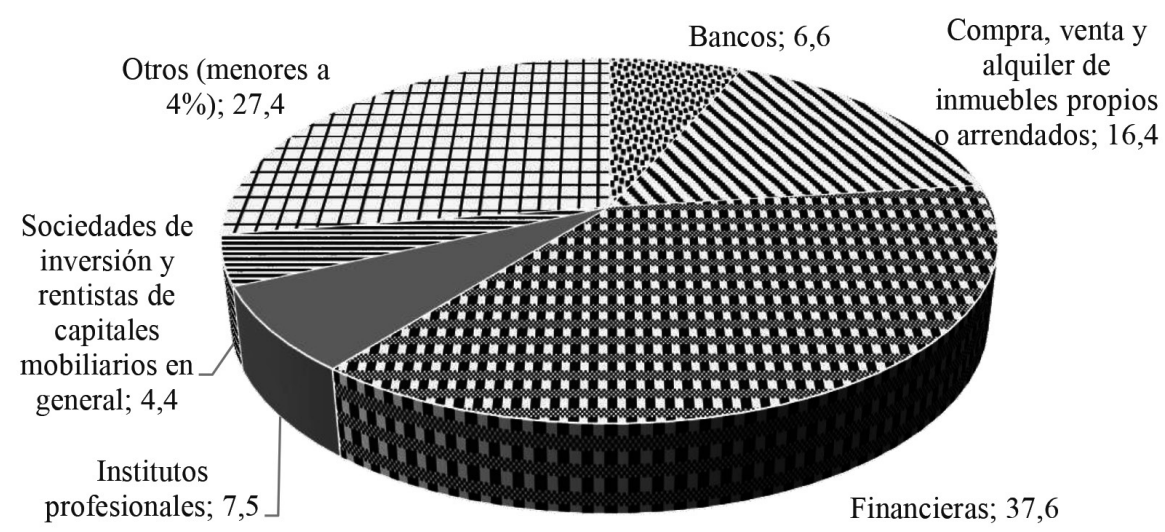

Ya veíamos que el tipo de sociedades civiles y/o comerciales dentro del procedimiento sumario es más diverso que respecto de los dos procedimientos ejecutivos u ordinarios. Ello se relaciona directamente con las actividades o rubros registrados ante el SII. En este sentido, el rubro de los bancos, de las sociedades dedicadas a la compra, venta y alquiler de inmuebles, así como de aquellas sociedades de inversión y rentistas de capitales mobiliarios en general, eran las principales actividades de las empresas en el procedimiento sumario. No obstante, en este procedimiento es posible ver una alta proporción de rubros (un 39\% 
en total) que individualmente no superan el 4\% (gráfico 8). Ello resulta aún más relevante si destacamos que un $40,2 \%$ de estas se encontraban en el registro PRO-PYME del SII (gráfico 5).

\section{GRÁFICO 8}

Actividades demandantes en procedimiento sumario según registro SII

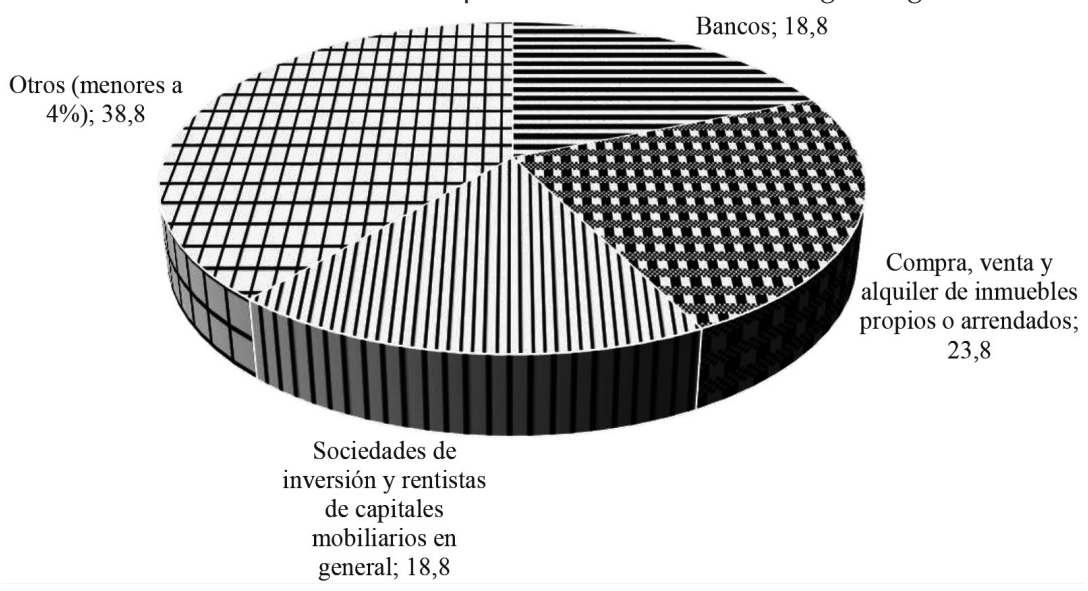

Finalmente, respecto de aquellas causas tramitadas bajo la categoría donde han sido agrupados los asuntos concursales y de quiebra, los rubros que ocupaban la mayor proporción no superaban un 3,6\% (leasing financiero, obras de ingeniería, obras menores en construcción, sociedades de inversión y rentistas de capitales mobiliarios en general, entre otros). En otras palabras, es posible observar una alta dispersión de actividades registradas. Este factor se relaciona a su vez con la mayor dispersión del tipo de personalidad jurídica, así como con el tamaño de las empresas solicitantes bajo estos procedimientos las que, como veíamos antes, en un 64\% estaban en el registro PRO-PYME del SII (gráfico 5).

La mayor diversidad de tipos y tamaños de empresas en los procedimientos sumarios y en aquellos concursales y/o de quiebra, dice relación, a su vez, con el tipo de materias que son tramitadas en cada uno de ellos. Así, mientras que en los procedimientos ejecutivos y ordinarios las principales causas tramitadas se relacionaban con el cobro (o preparación para el cobro) de títulos ejecutivos o de dinero respectivamente, en el caso del procedimiento sumario, y concursal y de quiebras, es posible observar diferencias importantes.

En primer lugar, respecto del procedimiento sumario, las principales materias se relacionan a temas de arriendo, donde un $75,7 \%$ de los demandantes eran personas naturales, un $23,4 \%$ personas jurídicas de derecho privado, y tan solo un $0,9 \%$ personas jurídicas de derecho público. Luego, y a mayor abundamiento, en aquellos casos donde el demandante en temas de arriendo eran sociedades civiles y comerciales, este tipo de causas incluían no solo a sociedades anónimas sino también a sociedades por acciones, así como a empresas en el registro PRO-PYME identificadas como tales (39,4\%). Otra materia relevante dentro de este procedimiento, la designación de árbitros (que ocupa un 22,6\% de este procedimiento en la muestra y un $19,3 \%$ de la población completa), también presentaba demandantes personas naturales como personas jurídicas de derecho privado (50\% cada uno). Dentro de 
estas últimas, en su mayoría se trata de sociedades anónimas y en bastante menor medida sociedades por acciones. Finalmente, respecto de esta materia, aquellas empresas categorizadas en el registro PRO-PYME alcanzaban un 31\%.

En segundo lugar, en los procedimientos concursales y/o de quiebra el tipo de demandante, o más bien solicitante, se relaciona aún más a la materia por la cual el ejerció su derecho a la acción. Así, el principal asunto tramitado en esta categoría era la liquidación voluntaria de persona natural $(40,5 \%)$, donde la totalidad de demandantes, lógicamente, eran personas naturales. El siguiente asunto tramitado en términos de frecuencia fue la liquidación voluntaria de empresa deudora $(27,4 \%)$, donde el 50,8\% de los solicitantes eran personas naturales y el $49,2 \%$ eran personas jurídicas. De estas últimas, en esta materia un 97\% de las empresas solicitantes eran consideradas como PYMES en el registro del SII. Retomando el punto anteriormente anunciado, ello da cuenta de una diferencia entre los usuarios del sistema cuando se trata de empresas. Mientras en el procedimiento ejecutivo y ordinario se trata de grandes empresas, sociedades anónimas ligadas al rubro financiero, en este último procedimiento se trata empresas de menor tamaño, de rubros más bien diversos, y que concurren a la justicia como parte del estado de insolvencia en que se encuentran. Como vemos, entonces, la mayor dispersión del tipo de personalidad en estos procedimientos, así como del tipo de empresas en particular, se relaciona directamente con las materias tramitadas.

En comparación con las empresas, cuando los demandantes eran personas naturales hay algunas particularidades que vale la pena destacar. Así, respecto a su actividad económica, la mayoría tenía como actividad "otras actividades de servicios personales" de acuerdo al registro del SII. Ello ocurría tanto en el procedimiento sumario (26,1\%) como en aquellos concursales y/o de quiebras (35\%), donde la mayor parte de los sujetos activos se trata de dicho tipo de personas. Más allá de esta categoría, es posible observar una alta variedad de actividades registradas (hasta 42 ) de las cuales ninguna considerada individualmente supera el $8 \%$.

Un cuarto criterio para caracterizar a los demandantes, y en particular a las empresas, fue clasificarlas en "jugadores frecuentes”. Para ello, he agrupado a aquellas que presentan más de 10 demandas de la muestra durante el período observado. 16 sociedades civiles y/o comerciales que aparecen en la muestra se encontraban en esa condición. 10 de ellas había presentado entre 10 a 20, 2 jugadores frecuentes presentaron entre 20 y 30, una de ellas 53 demandas, y un solo demandado presentó 89. Luego, las demandas que presentaron estos demandantes (que van entre 10 a 89 demandas), fueron iniciadas fundamentalmente en los procedimientos ejecutivos u ordinarios. Por el contrario, gran parte de las demandas en los procedimientos sumarios y concursales fueron presentadas por demandantes fuera de esa categoría (gráfico 9). 


\section{GRÁFICO 9}

Proporción de demandas presentadas por jugadores frecuentes por tipo de procedimiento

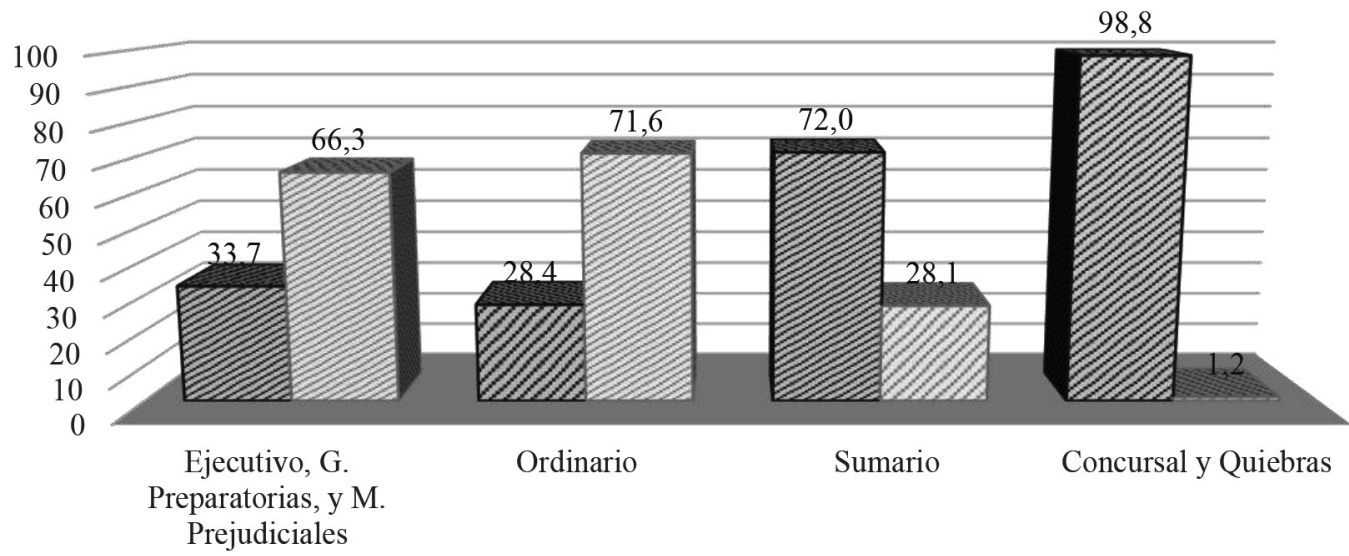

№ $ه \mathrm{Si}$

Un quinto factor consistió en tratar de determinar la cuantía demandada en cada una de las causas que componen la muestra. Esta variable es muy compleja de determinar por lo que solo fue posible hacerlo en un número reducido de casos ${ }^{49}$. Sin embargo, y dada la inexistencia de otros estudios donde se dé cuenta de esta variable, es que vale la pena destacar los resultados en esta muestra a pesar del menor nivel de confiabilidad.

En el procedimiento ejecutivo la cuantía promedio fue de \$7.539.989. Sin embargo, se trata de un valor altamente influenciado por dos causas cuya cuantía superaban los 100 millones de pesos (sin estas, el promedio es de \$4.015.284). Luego, la mayor proporción de casos se encontraba entre 1 y 2 millones (27\%) y 2 a 3 millones (19,5\%), encontrándose el $75 \%$ de los casos bajo los $\$ 5.108 .762$. En el caso del procedimiento ordinario el rango era aún mayor. De esta manera, es relevante destacar que el $90 \%$ de los casos se encontraba bajo los \$8.247.400 aun cuando el promedio era de más de 28 mil millones de pesos, producto cinco casos con cuantías de miles de millones de pesos (sin estos, de hecho, el promedio era de \$3.276.513). Al igual que en el procedimiento ejecutivo, la mayor parte de causas en este procedimiento se encontraba entre 1 y 2 millones con un 37\%. Finalmente, el procedimiento sumario también presenta un rango de cuantías extremadamente amplio que dificultan calcular un punto medio real (sin los cuales el promedio es de \$7.271.797). A pesar de estos valores extremos, gran parte de los casos se encontraba bajo los $\$ 7.773 .028$ (75\%). A diferencia de los anteriores, la mayor parte de las demandas presentaba cuantías entre 100 mil y 1 millón de pesos (27,9\%), y en segundo lugar entre 1 y 2 millones (18,9\%).

\footnotetext{
49 Porque la primera resolución del tribunal o no fija la cuantía o simplemente señala que esta es indeterminada, porque no fue posible acceder a la demanda vía el sitio Web del Poder Judicial por encontrarse archivada, entre otros factores.
} 
TABLA 5

Cuantía de las demandas ingresadas por tipo de procedimiento

\begin{tabular}{|c|c|c|c|}
\hline & $\begin{array}{c}\text { Ejecutivo, G. } \\
\text { Preparatorias, y M. } \\
\text { Prejudiciales }\end{array}$ & Ordinario & Sumario \\
\hline Valor mínimo (\$) & 59.796 & 64.367 & 26.652 \\
\hline Valor Máximo (\$) & 169.334 .841 & 3.752 .000 .000 .000 & 257.000.000.000 \\
\hline Promedio(\$) & 7.539 .989 & 28.749.945.014 & 6.421 .424 .165 \\
\hline Mediana (\$) & 2.382 .915 & 1.673 .565 & 2.247 .750 \\
\hline Desviación estándar (\$) & 22.799 .458 & 283.310.031.903 & 34.969 .141 .710 \\
\hline Total de causas & 77 & 186 & 111 \\
\hline
\end{tabular}

Un sexto factor utilizado para caracterizar a los demandantes fue la comuna de su domicilio. En aquellas donde el demandante era una empresa, la principal comuna de procedencia era Santiago, seguido de Providencia y Las Condes. Tan solo en los procedimientos concursales y de quiebras es posible encontrar mayor diversidad. En cambio, en aquellos casos donde el demandante era personas naturales, la situación es diversa. En el procedimiento sumario y en el procedimiento concursal y/o de quiebras, donde hay mayor presencia de personas naturales, si bien la mayor parte de los demandantes también tenían su domicilio en la ciudad de Santiago, esta proporción no solo no supera el 31\% sino también es posible observar mayor presencia de comunas y una gran dispersión entre ellas (gráfico 10).

\section{GRÁFICO 10}

Comunas de procedencia demandantes personas naturales

(Procedimiento Sumario . Concursal y quiebras)

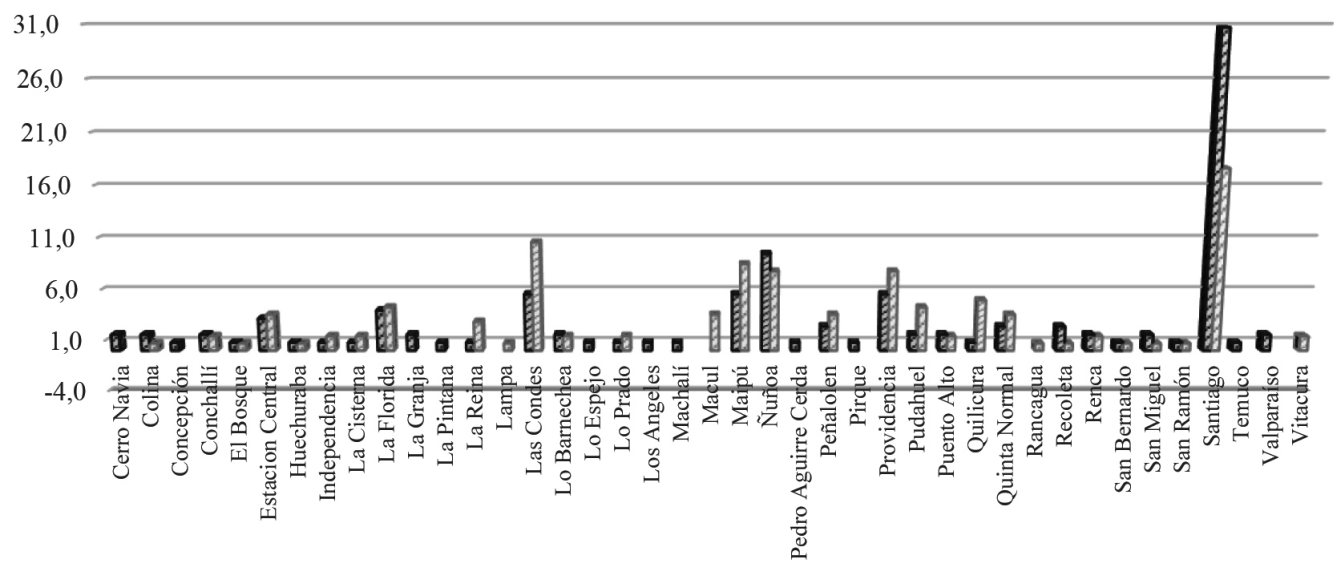

\$Sumario \$Concursal y quiebra 


\subsection{QuiEnes ERAN los DEMANDADOS}

Del total de la muestra, 812 causas tenían al menos un demandado. Tan solo una proporción menor de estas presentaba más de dos demandados $(4,8 \%)$, siendo el máximo registrado un total de 5 (tan solo en 4 causas). De los casos con más de un demandado, en prácticamente todos había al menos un demandado que era persona natural.

En relación al tipo de personalidad, es posible afirmar que con excepción del procedimiento concursal y de quiebras, estos son en su mayoría personas naturales. Tan solo en el caso de este último, donde la proporción de causas con demandados es bastante menor $(21,9 \%)$, estos se trataban en su mayoría de empresas (61\% S.A., 26,5\% sociedades de responsabilidad limitada, $10 \%$ sociedades por acciones). Cabe destacar, además, que las empresas demandadas en este procedimiento estaban mayoritariamente identificadas en el registro PRO-PYME del SII (86,5\%).

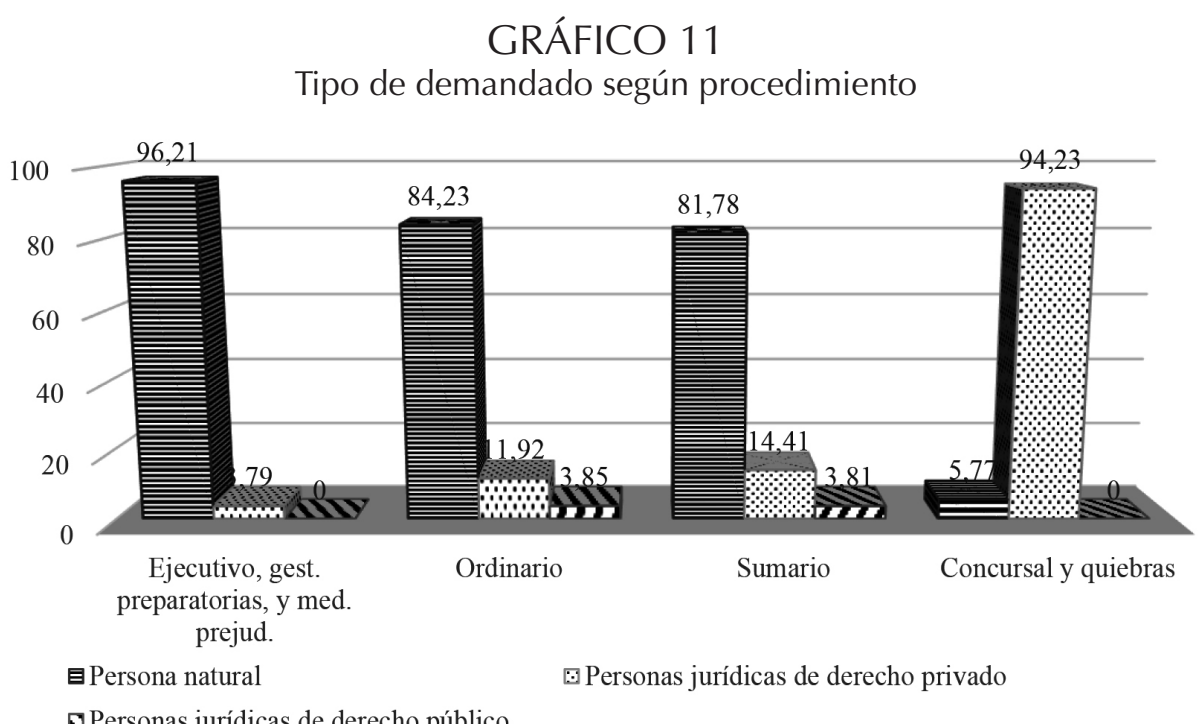

Test $\mathrm{Chi}^{2} \mathrm{P}=0,000$

En este punto es posible entonces terminar de confirmar la hipótesis respecto a que no solo los demandantes son principalmente empresas sino que además los demandados serían fundamentalmente personas naturales. Tal como puede observarse en el gráfico 11, ello ocurre tanto en el procedimiento ejecutivo, como ordinario y sumario con alta significancia estadística. Por el contrario, en los asuntos concursales y de quiebra, al menos respecto de aquellos asuntos donde hay demandados, estos no serían personas naturales si no que, y como veríamos con anterioridad, serían empresas (Tabla 8). 
TABLA 6

Demandados personas naturales por procedimiento

$\begin{array}{lcccc}\begin{array}{c}\text { Demandado es persona } \\ \text { natural }\end{array} & \begin{array}{c}\text { Ejecutivo, G. } \\ \text { Preparatorias, y M. } \\ \text { Prejudiciales }\end{array} & \text { Ordinario } & \text { Sumario } & \begin{array}{c}\text { Concursal y } \\ \text { Quiebras }\end{array} \\ \text { No } & 3,8 & 15,8 & 19,3 & 98,7 \\ \mathrm{Si} & 96,2^{*} & 84,2^{*} & 80,8^{*} & 1,27^{*} \\ \text { Test Chi }{ }^{2} P=0,000 & 100 & 100 & 100 & 100 \\ * \text { (IC de 95\%) } & & & & \\ \text { Z-Test (proporción) } & .9390931 & .7980079 & .7575499 & -.0015747 \\ P=0,000 & .9851494 & .8866075 & .8575128 & .0268912\end{array}$

A partir de estos datos, hay que destacar que el procedimiento sumario se trata de una categoría donde no solo la mayoría de demandantes son personas naturales, sino también donde los demandados lo son. En otras palabras, es un procedimiento que principalmente es usado entre ciudadanas o ciudadanos. Ello ocurría en el 93\% de los casos, mientras que personas jurídicas de derecho privado o público aparecen en una proporción muy menor. En el caso contrario, es decir cuando los demandantes no eran personas naturales, el principal tipo de demandado si lo era (tabla 9).

TABLA 7

Tipo de demandado en casos con demandante persona natural procedimiento sumario

\begin{tabular}{lcccr}
\hline & & \multicolumn{2}{c}{ Tipo de demandado } \\
\hline $\begin{array}{c}\text { Demandante persona } \\
\text { natural }\end{array}$ & Persona natural & $\begin{array}{c}\text { Persona jurídica de } \\
\text { derecho privado }\end{array}$ & $\begin{array}{c}\text { Persona jurídica de } \\
\text { derecho público } \\
(\%)\end{array}$ & Total \\
\hline No $(\%)$ & $62(65,3)$ & $26(27,4)$ & $7(7,4)$ & $95(100)$ \\
Si $(\%)$ & $131(92,9)$ & $8(5,7)$ & $2(1,4)$ & $141(100)$ \\
\hline Total & 193 & 34 & 9 & 236 \\
Test Chi2 $\mathrm{P}=0,000$ & & & & \\
\hline
\end{tabular}

En términos de las actividades económicas de los demandados en aquellos casos en que eran personas naturales, ocurre algo similar a lo que señalaba respecto de los demandantes. La principal categoría en los tres procedimientos donde hay mayor prevalencia de este tipo de demandados era "otras actividades de servicios personales", y luego de eso es posible observar una alta dispersión de actividades que consideradas individualmente no superan el 3\%.

De aquellas causas donde fue posible identificar la comuna de procedencia del demandado (430 en el caso de personas naturales y 122 respecto de empresas), se observa que es la comuna de Santiago la principal. No obstante, en el caso de las personas naturales la proporción es bastante menor y con una alta dispersión (habiendo varias de ellas que por no superar el $2 \%$ no fueron incluidas en el gráfico 12). Por el contrario, en el caso de las empresas, además de Santiago, los demandados se concentraban en Las Condes y Providencia. 
GRÁFICO 12

Principales comunas de procedencia demandados

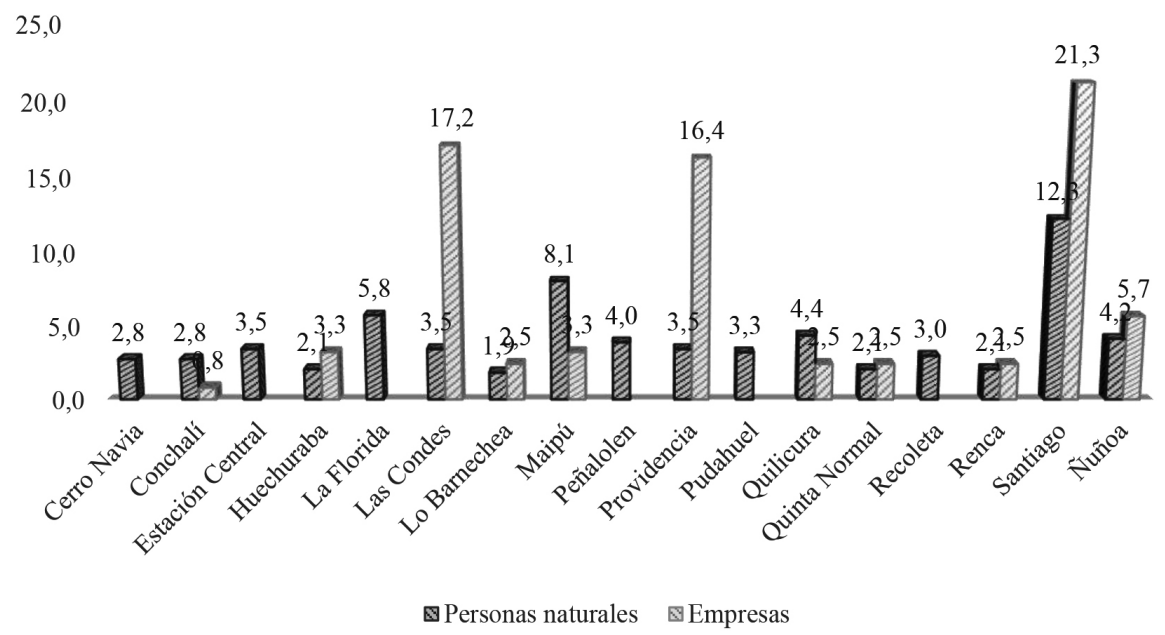

En relación a los demandados cuando eran personas naturales, en el procedimiento ejecutivo se encontraban en el grupo de entre 30 a 49 años. Por su parte, en el procedimiento ordinario se distribuyen de manera más bien uniforme entre las categorías correspondientes entre 30 a 69 años. Finalmente, en el procedimiento sumario los demandados se encuentran mayormente entre los 40 a 49 y 50 a 59 años (tabla 10).

TABLA 8

Edad personas naturales como demandados según grupo etáreo

\begin{tabular}{crrr}
\hline & $\begin{array}{c}\text { Ejecutivo, G. Preparatorias, y M. } \\
\text { Prejudiciales }(\%)\end{array}$ & Ordinario (\%) & Sumario (\%) \\
\hline 20 a 29 años & $22(8,9)$ & $9(4,4)$ & $7(4)$ \\
30 a 39 años & $67(27,2)$ & $50(24,2)$ & $32(18,3)$ \\
40 a 49 años & $75(30,49)$ & $49(23,7)$ & $46(26,3)$ \\
50 a 59 años & $54(22)$ & $45(21,7)$ & $44(25,1)$ \\
60 a 69 años & $19(7,7)$ & $41(19,8)$ & $29(16,6)$ \\
70 a 79 años & $7(2,8)$ & $7(3,4)$ & $14(8)$ \\
80 a 89 años & $2(0,8)$ & $3(1,5)$ & $3(1,7)$ \\
Más de 90 & & $3(1,5)$ & \\
Total & $246(100)$ & $207(100)$ & $175(100)$
\end{tabular}

Test $\mathrm{Chi}^{2} P=0,001$

En relación al sexo de los demandados, aun cuando en su mayoría eran hombres no es sencillo en este caso afirmar que las diferencias observadas sean estadísticamente relevantes. De esta manera, si bien en el procedimiento ejecutivo como en el ordinario la proporción de mujeres es menor, el intervalo de confianza no alcanza a desechar que la proporción sea 
equitativa entre ambos sexos. Luego, el procedimiento sumario es el único procedimiento donde es posible afirmar esto con un alto nivel de significancia estadística (tabla 11).

TABLA 9

Sexo demandado personas naturales por tipo de procedimiento

\begin{tabular}{lccc}
\hline & $\begin{array}{c}\text { Ejecutivo, G. Preparatorias, } \\
\text { y M. Prejudiciales }(\%)\end{array}$ & $\begin{array}{c}\text { Ordinario } \\
(\%)\end{array}$ & $\begin{array}{c}\text { Sumario } \\
(\%)\end{array}$ \\
\hline Mujer & $111(43,9)$ & $96(44,2)$ & $74(38)$ \\
Hombre & $142(56,1)$ & $121(55,8)$ & $119(62)$ \\
\hline Total & $253(100)$ & $217(100)$ & $192(100)$ \\
Test Chi ${ }^{2} P=0,362$ & & & \\
(IC de 95\%) & $.3775885-.4998819$ & $.3763138-.5084789$ & $.311544-.4488727$ \\
Z-Test (proporción) & $P=0,0257$ & $P=0,0448$ & $P=0,0005$ \\
\hline
\end{tabular}

Los resultados obtenidos dan cuenta de que, en los tribunales civiles de la jurisdicción de la Corte de Apelaciones de Santiago, los demandados no solo se tratan de personas naturales, sino que, además, estos en general no comparecen. Ya sea porque se trata de demandas que ni siquiera se notifican (en el $89 \%$ y $87 \%$ en los procedimientos ejecutivos y ordinarios) o incluso habiendo sido notificados (en sumario, por ejemplo, en un $22 \%$ ). En general, se comparece y opone excepciones en porcentajes marginales, salvo en el procedimiento sumario (33\%) y en los procedimientos concursales y de quiebras (30\%) (Tabla 12). En este punto no es posible observar diferencias según si se trata de empresas o personas naturales como demandados (tabla 12). 
TABLA 10

Actitud del demandado según tipo de procedimiento (\%)

\begin{tabular}{|c|c|c|c|c|}
\hline Actitud demandado & $\begin{array}{c}\text { Ejecutivo, G. Preparatorias, } \\
\text { y M. Prejudiciales }\end{array}$ & Ordinario & Sumario & $\begin{array}{l}\text { Concursal y } \\
\text { Quiebras }\end{array}$ \\
\hline $\begin{array}{l}\text { Contesta demanda y/u } \\
\text { opone excepciones }\end{array}$ & $10(3,8)$ & $20(7,7)$ & $72(33,1)$ & $16(30,2)$ \\
\hline $\begin{array}{l}\text { No comparece habiendo } \\
\text { sido notificado }\end{array}$ & $17(6,4)$ & $14(5,4)$ & $53(22,4)$ & $5(9,4)$ \\
\hline $\begin{array}{l}\text { No comparece sin haber } \\
\text { estado notificado }\end{array}$ & $236(89,4)$ & $226(86,9)$ & $106(44,7)$ & $32(60,4)$ \\
\hline $\begin{array}{l}\text { No comparece estando } \\
\text { notificado y dentro de } \\
\text { plazo }\end{array}$ & $1(0,4)$ & 0 & $6(2,53)$ & 0 \\
\hline $\begin{array}{l}\text { Total } \\
\text { Test } \text { Chi }^{2} P=0,000 \\
\text { Fisher's exact } P=0,0026\end{array}$ & $180(100)$ & $150(100)$ & $117(100)$ & $53(100)$ \\
\hline
\end{tabular}

\section{ALGUNAS REFLEXIONES A PARTIR DE LOS HALLAZGOS. FUNDAMENTOS PARA REORIENTAR LA JUSTICIA CIVIL}

Los resultados de este estudio empírico de carácter observacional dan cuenta de que los principales usuarios de la justicia civil en Chile son sociedades anónimas, grandes empresas (o al menos no registradas como PYME en el SII), del sector financiero, con domicilio en la comuna de Santiago, que presentan causas fundamentalmente relacionadas con el cobro de dinero. Normalmente, además, se trata de lo que he caracterizado como "jugadores frecuentes". Tan solo en los procedimientos sumarios y concursales y/o de quiebra es posible encontrar mayor diversidad de sujetos activos. Por el otro lado, los asuntos civiles se tratan en su mayoría de causas donde los demandados eran personas naturales provenientes de diversas comunas y rubros, que raramente comparecen defendiéndose porque ni siquiera son notificados. Sumado al hecho de que gran parte de estas causas son consideradas como de "tramitación masiva", ello habla de que no se trata de un problema de congestión o sobre carga, sino simplemente de para qué es utilizada día la justicia civil y por quién. En otras palabras, de la poca relevancia que tiene nuestra justicia civil no solo desde el punto de vista de quienes no lo utilizan, sino también desde el punto de vista de quienes pueden hacerlo.

No es fácil explicar la situación de la justicia civil en Chile. Respecto al por qué gran parte de los usuarios son empresas en gestiones relacionadas a la cobranza, la respuesta ya ha sido avanzada en la literatura nacional. Así, de acuerdo a un estudio la "sobre utilización" del sistema con este tipo de causas se explicaría por las formalidades administrativas exigidas por la ley para mantener vivo un crédito cobrable ${ }^{50}$. A esto podría agregarse la posibilidad de que la justicia civil sea parte de una estrategia de cobro más amplia (y en ese sentido extra judicial), por ejemplo como un antecedente utilizado para luego realizar contactos telefónicos o presenciales frente al deudor. Dada la falta de tasas judiciales y bajo

50 Pontificia Universidad Católica de Valparaíso (2012) pp. 13-14. 
costo por causa que representa para las grandes empresas contratar servicios de cobranza masiva, aprovechando la economía de escala, así como por el desconocimiento por parte de deudores de estos procedimientos, los tribunales serían una herramienta ideal para presionar el pago y cumplimiento de obligaciones monetarias ${ }^{51}$. Esto es particularmente cierto respecto de los "jugadores frecuentes." A esto se puede sumar el cumplimiento con regulaciones tributarias ante el SII con el objeto de declarar deudas incobrables con fines netamente tributarios ${ }^{52}$. Esta línea argumental permitiría entender el por qué la alta proporción de demandados que no comparecen porque ni siquiera son notificados.

Menos claro resulta responder por qué estas grandes empresas no resuelven otro tipo de controversias ante la justicia civil. A este respecto, una alternativa a explorar y de la cual no hay estudios empíricos relevantes, es el crecimiento del arbitraje civil y comercial en nuestro país el cual, además, se ha señalado presentaría una serie de ventajas entre las que destacan la privacidad en que operan y el carácter técnico o experto de los árbitros en las diversas temáticas por las cuales son requeridos. ${ }^{53}$ Para algunos autores, todavía, la adjudicación privada presentaría ventajas intrínsecas respecto de la provisión pública de justicia. Así, Bryan Caplan y Edward Stringham señalan que la adjudicación privada puede ser más eficiente al ser más flexible respecto de las diversas necesidades del "consumidor" de justicia y del tipo de conflicto según su complejidad ${ }^{54}$.

Por qué no hay más personas naturales ejerciendo su derecho a la acción es otra historia. Estos, como lo viene señalando la literatura en nuestro país y a nivel comparado, se encuentran alejados por diversas barreras como la falta de información cuáles son y cómo hacer valer sus derechos; la ubicación de los tribunales, el formalismo y rigidez del procedimiento escrito, la duración de los procesos, y la necesidad, ya sea legal o práctica, de contar con un abogado para llegar siquiera a los tribunales o, al menos, de obtener algún resultado. Todo lo anterior genera que en un análisis costo beneficio, entre el tiempo que es necesario invertir y los costos asociados a la litigación, el litigante esporádico no ocupe los tribunales para solucionar necesidades legales. Esto se ve, por ejemplo, en que el único procedimiento con mayor participación de personas naturales es en el sumario, donde la ley permite, en algunos casos, la comparecencia personal ${ }^{55}$. Me parece que estas explicaciones son perfectamente aplicables a las pequeñas y medianas empresas, en tanto también es de esperar que sean litigantes esporádicos que no pueden darse el lujo de la litigación civil como mecanismo regular de resolución de controversias frente a otras empresas. Urge, sin embargo, mayor investigación respecto a las necesidades legales insatisfechas, barreras de acceso y factores que permitan explicar y decidir políticas públicas enfocadas específicamente en este potencial tipo de usuarios.

51 Pontificia Universidad Católica de Valparaíso (2012) pp. 13-14.

52 Véase, en este sentido: Circular No 24 del 24 de Abril de 2008. Disponible en: http://www.sii.cl/documentos/circulares/2008/circu24.htm Fecha de consulta: 31 de julio de 2018.

53 Sin embargo, hay autores que han descrito un fenómeno de expansión en el arbitraje. Véase: LETURIA (2006) p. 266. Sobre las ventajas del arbitraje, véase: VArgas (2001) pp. 2-6; Moyer y SteWArt (2003) p. 652; DAKOLIAS (1995) p. 200.

54 Caplan y Stringham (2008) pp. 518-520.

55 Ley No 18.101, Ley de Arrendamiento de Predios Urbanos, Art. 8. 
Más allá de lo que ocurre en el procedimiento sumario, donde veíamos se trata fundamentalmente de asuntos en temas de arrendamiento, pero también donde se litigan causas de baja proporción en el ingreso pero de alto impacto como las acciones colectivas en materia de consumidor (que ocupa un $0,15 \%$ del ingreso en el procedimiento sumario), el centro de las actividades de la justicia civil gira en torno a la cobranza.

La doctrina procesal reconoce que la principal función de la justicia civil es resolver conflictos de relevancia jurídica mediante una decisión de autoridad ${ }^{56}$. No obstante hoy en día es posible concebir una función jurisdiccional más amplia que la mera resolución de una disputa entre privados ${ }^{57}$, sería esperable que ese tipo de asuntos ocupen una parte considerable del sistema. Por el contrario, en los hechos, aun sumando el procedimiento ordinario y sumario, que serían aquellos diseñados para que los jueces civiles cumplan dicha tarea, estos tienen una prevalencia muy menor en el sistema $(7,9 \%$ del total del ingreso civil entre los años 2014 a 2016).

Por supuesto, que el sistema de justicia civil permita que las empresas cobren sus créditos o al menos declaren su incobrabilidad para efectos tributarios, no es algo esencialmente negativo. Ello puede resultar deseable para el correcto funcionamiento del mercado en tanto facilitaría el intercambio económico en un entorno de certeza de que ante el incumplimiento el sistema brindará una respuesta. La pregunta es si creemos que ese sería el único rol que debería estar cumpliendo la justicia civil.

La justicia civil debería ser un espacio para casos simples y complejos, sufridos por empresas grandes, medianas, y pequeñas, así como por personas naturales. Desde otro punto de vista, debería reflejar la complejidad inherente de un sistema civil, tanto en términos de los potenciales actores que interactúan en base a intereses e incentivos complejos de determinar ${ }^{58}$, como por los diversos vínculos entre el ciudadano, las empresas, y el Estado, que pueden darse ante este tipo de tribunales ${ }^{59}$. En relación a lo anterior, debería reflejar la diversidad de asuntos que podrían ser conocidos por la justicia civil, dada la diversidad de leyes sustantivas que son de su competencia, o por las diversas finalidades que el ejercicio de la acción puede tener ${ }^{60}$. Ello daría cuenta de un sistema de justicia civil en correcto funcionamiento, donde se cumplan tanto los fines privados, propios de las partes litigantes, pero también sus fines públicos. Es justamente de la comparación entre lo que hoy día conoce mayoritariamente la justicia civil frente a las funciones que debería cumplir, surge el relato de la crisis de la justicia civil chilena.

La pregunta central a la hora de pretender mejorar o superar el estado de crisis antes descrito, es el por qué el Estado debería financiar un sistema de justicia civil en condiciones de correcto funcionamiento. Me parece que hay, al menos, dos puntos de vista a analizar. Primero porque el acceso a un proceso judicial hoy en día es considerado como un derecho

\footnotetext{
56 Couture (2014) p. 9. Por ejemplo, en nuestro medio: Colombo (1991) p. 41.

57 En una concepción de jurisdicción que va más allá de resolver disputas mediante el proceso judicial, véase: BORDALí (2009) pp. 219-224.

58 Para una caracterización de la litigación civil en Chile desde el punto de vista de análisis económico del derecho, véase: Mery (2006) pp. 83-136.

59 Genn (2010) p. 8.

${ }^{60}$ Couture (2014) pp. 81-82.
} 
humano. Desde esta perspectiva, sería un derecho que tendría todo individuo para promover sus legítimas pretensiones en el foro que resulte apropiado, o defenderse de las de otros de manera efectiva ${ }^{61}$. Segundo, porque debe cumplir funciones relevantes para el Estado de Derecho. Como veremos, la mayor parte de las diversas concepciones que se tiene sobre este principio incluye de alguna u otra manera el acceso a la justicia como uno de sus pilares fundamentales ${ }^{62}$.

Desde este primer punto de vista, resulta relevante definir los contornos del acceso a la justicia como derecho fundamental. Sin embargo, definir exactamente qué se entiende por tal es un desafío complejo en tanto no ha sido definido o garantizado expresamente ni en los instrumentos del sistema universal, interamericano, ni europeo, sino que su construcción ha sido elaborada fundamentalmente de manera jurisprudencial y doctrinaria ${ }^{63}$. En nuestro país, el acceso a la justicia como derecho fundamental no se encuentra expresamente regulado en la Constitución. Luego, se trata más bien de una construcción normativa que ha realizado la doctrina y jurisprudencia chilena a partir de los artículos 19 No 3 y 76 de la Constitución ${ }^{64}$, así como de la incorporación o recepción de fuentes del Derecho Internacional de los Derechos Humanos. ${ }^{65}$ Ambas normas son complejas en cuanto a su contenido ya que de ellas se han concebido una serie de derechos e instituciones jurídicas diversas (inexcusabilidad judicial, debido proceso, igualdad ante la ley, derecho a la defensa, etc.), que además por sus características propias, no se tratan de reglas sino más bien de principios y estándares de textura abierta, donde el acceso a la justicia no es sino solo una de estas manifestaciones ${ }^{66}$. Recogiendo la evolución constitucional a nivel nacional (a partir de las Constituciones del siglo XIX), se agrega además la utilización de medios alternativos de resolución de conflictos como la conciliación ${ }^{67}$. Todos estos factores sin duda complican el análisis dado que el desarrollo interpretativo que ha hecho la doctrina y jurisprudencia.

Desde un punto de vista formal, el acceso a la justicia se le suele analizar desde la capacidad efectiva que tendrían o no los individuos para acudir a los tribunales propiamente tales para obtener una resolución justa sobre un conflicto o disputa entre diversos actores ${ }^{68}$. En este sentido, la provisión del proceso judicial como mecanismo de resolución de dispu-

61 Trebilcock et al. (2012), p. 3.

62 Trebilcock et al. (2012), p. 3.

63 No fue sino hasta el denominado Tratado de Lisboa del año 2007, en el marco de la Unión Europea, donde menciona este derecho de manera expresa en sus artículos 67 y 81. Esto, al menos en su versión en inglés, en tanto que en la versión en español se habla de tutela judicial. Véase: Agencia de los Derechos Fundamentales de La Unión Europea (2011) p. 15.

64 García y Contreras (2013) p. 246.

65 Así por ejemplo, en las Actas Oficiales de la Comisión Constituyente, Silva Bascuñán describía la influencia que tuvo la Declaración Universal de Derechos Humanos y la Declaración Americana de Derechos y Deberes del Hombre, en la redacción original del artículo 19 № 3 y 76. Véase: Actas Oficiales de la Comisión Constituyente, Sesión 100a, Celebrada en lunes 6 de enero de 1975, p. 4.

66 Siguiendo la famosa distinción de Ronald Dworkin. Véase: Dworkin (1977) pp. 22-31.

67 Bates (1992) p. 166.

68 PASTOR (2006) p. 417. En el ámbito nacional, este aspecto restringido del acceso ha sido recogido en la jurisprudencia del Tribunal Constitucional, y se le ha llamado derecho de acceso al órgano jurisdiccional, derecho a la acción, derecho a la tutela judicial, o derecho al proceso. Véase: Bordalí (2011) pp. 312, 330. 
tas constituye una obligación positiva del Estado como consecuencia de la prohibición de la autotutela. Si es el Estado quién por regla general les impide a las personas dar efectividad a sus derechos por mano propia, es quien entonces debe garantizar la provisión de un servicio judicial ${ }^{69}$. Así por ejemplo, Andrés Bordalí define el acceso a la justicia como “... la exigencia de abrir la 'puerta' de los tribunales a todo tipo de derecho o interés que pueda requerir de tutela estatal”70.

En términos de un ámbito más restringido de aplicación, esto es, desde el punto de vista del acceso del individuo a los tribunales de justicia (en oposición a una visión amplia que incluya otros medios de resolución de $\operatorname{conflictos}^{71}$ ), este derecho ha sido denominado y asimilado a diversas instituciones procesales y constitucionales. Así, se le ha llamado derecho de acceso al órgano jurisdiccional, derecho a la acción, derecho a la tutela judicial, o derecho al proceso $^{72}$. Concebido el acceso a la justicia como un derecho de los individuos de acudir o de ser oído por los tribunales de justicia para la resolución de sus conflictos o necesidades legales ${ }^{73}$, hay una serie de garantías procesales que van orientadas a que el ciudadano pueda llegar a los tribunales y pueda sostener su caso hasta ver satisfecha su pretensión bajo un criterio de efectividad, esto es, de manera que el derecho no sea ilusorio o meramente nominal ${ }^{74}$. A partir de esta idea, particularmente relevante ha sido la relación entre acceso a la justicia y la denominada tutela judicial efectiva, proveniente del artículo 24 de la Constitución Española ${ }^{75}$ y que ha tenido gran influencia en la jurisprudencia del Tribunal Constitucional chileno ${ }^{76}$.

Más allá de las dificultades dogmáticas para delimitar el concepto del acceso a la justicia, pareciera que lo relevante es que tanto a nivel internacional, dentro del sistema universal, ${ }^{77}$ interamericano, ${ }^{78}$ y europeo, ${ }^{79}$ al menos, como también a nivel nacional, ${ }^{80}$ se reconoce que se trata de un derecho humano y que como tal entabla obligaciones tanto po-

\footnotetext{
69 Couture (1950) p. 7.

0 Bordalí (2011) p. 330.

1 Véase: PNUD (2005) p. 14.

72 Bordalí (2011) p. 312.

73 En este sentido: Tribunal Constitucional, Rol No 2688-2014, Sentencia del 27 de enero de 2015, c. 5.

74 Tribunal Constitucional, Rol No 1046-2008, Sentencia del 22 de junio de 2008, c. 20. En el mismo sentido: Tribunal Constitucional, Rol No 1061-2008, Sentencia del 28 de agosto de 2008, c. 15; Tribunal Constitucional, Rol No 2438-2013, Sentencia del 10 de abril de 2014, c. 11.

75 Artículo 24 No 1: Todas las personas tienen derecho a obtener la tutela efectiva de los jueces y tribunales en el ejercicio de sus derechos e intereses legítimos, sin que, en ningún caso, pueda producirse indefensión. Sobre la tutela judicial efectiva en la doctrina y jurisprudencia de España, véase: GonZÁlez (1984) pp. 44, 45; Montero Aroca (2016) p. 197.

76 Por más interesante que es este debate acerca de la naturaleza normativa en tanto derecho fundamental, y sobre todo con la idea de focalizar mi trabajo en el objetivo presentado en la introducción, es que he preferido no profundizar en ello. Además, en nuestro país se ha desarrollado ya con bastante profundidad en los siguientes trabajos que sugiero visitar: Bordalí (2011) y García y Contreras (2013).

77 Asamblea General de las Naciones Unidas (2012) p. 4.

78 Instituto Interamericano de Derechos Humanos et al. (2010), pp. 18-23.

79 Agencia de los Derechos Fundamentales de la Unión Europea (2016) pp. 16-20.

80 García y Contreras (2013) p. 246.
} 
sitivas como negativas de parte del Estado. ${ }^{81} \mathrm{Tal}$ como ha sido reconocido en el Derecho Internacional de los Derechos Humanos, las contravenciones al derecho de acceso a la justicia no solo pueden provenir de disposiciones legales que la contravengan, sino que también prácticas de hecho que deriven en obstáculos pueden constituir violaciones a los derechos consagrados $^{82}$. De esta manera, en el sistema interamericano de protección de los derechos humanos, en base al mismo principio, se ha reconocido que las barreras de acceso pueden ser directas o indirectas, de iure o de facto ${ }^{83}$.

Más allá del de la eliminación o no imposición de barreras u obstáculos que impidan que el individuo pueda llegar a los tribunales, el acceso a la justicia como derecho implica que se creen las condiciones para la protección de los derechos, no solo formalmente sino que de manera efectiva ${ }^{84}$. En nuestro país el Tribunal Constitucional chileno ha señalado que este derecho implica no tan solo la posibilidad de iniciar una acción en tribunales como única forma de garantizarlo, sino que también el acceso efectivo a la jurisdicción en todos los momentos de su ejercicio ${ }^{85}$.

Por supuesto, este derecho no tiene un carácter absoluto. De esta manera, el Tribunal Europeo ha desarrollado la idea de que es posible establecer restricciones, ${ }^{86}$ las cuales deben ser analizadas en términos de si las limitaciones impuestas vulneran o no la esencia del derecho de acceso, para lo cual se atenderá al objetivo que persiguen y la relación de proporcionalidad que este guarda con los medios empleados. ${ }^{87}$ En este mismo sentido se ha pronunciado más recientemente la Corte $\mathrm{IDH} .^{88} \mathrm{La}$ ley podría relativizar o condicionar el

81 Recalco este punto porque no ha sido siempre así. Por ejemplo, en el ámbito del Consejo de Europa, en el caso Golder v. United Kingdom del Tribunal Europeo de Derechos Humanos, uno de los argumentos del Gobierno era negar la existencia de ese derecho dentro del artículo $6^{\circ}$ del Convenio Europeo para la Protección de los Derechos Humanos y de las Libertades Fundamentales. GOLDER V. UNITED KINGDOM. Tribunal Europeo de Derechos Humanos. Sentencia de 21 de febrero de 1975, párr. 22.

82 GOLDER V. UNITED KINGDOM. Tribunal Europeo de Derechos Humanos. Sentencia de 21 de febrero de 1975, párr. 26. Este argumento sería profundizado en fallos posteriores: AIREY V. IRLANDA. Tribunal Europeo de Derechos Humanos. Sentencia del 9 de Octubre de 1979. MCVICAR V. UNITED KINGDOM. Tribunal Europeo de Derechos Humanos. Sentencia del 7 de Mayo de 2002; P, C AND S v. UNITED KINGDOM. Tribunal Europeo de Derechos Humanos. Sentencia del 16 de Julio de 2002; STEEL \& MORRIS V. UNITED KINGDOM, Tribunal Europeo de Derechos Humanos. Sentencia del 15 de Febrero de 2005.

83 Fernández Ortega y Otros vs. México. Corte Interamericana de Derechos Humanos. Sentencia del 30 de agosto de 2010, párr. 201.

84 Julius Kloiber Schlachthof GMBH and Others v. Austria. Tribunal Europeo de Derechos Humanos. Sentencia del 4 de abril de 2013, párr. 28. Agencia de los Derechos Fundamentales de la Unión Europea (2016) p. 48. En este mismo sentido: CLAUDE REYES Y otRos vs. ChILE. Corte Interamericana de Derechos Humanos. Sentencia del 19 de septiembre de 2006, párr. 127.

85 Requerimiento de inaplicabilidad por inconstitucionalidad de EDUARdo Hemmelmann Troncoso, respecto de los artículos 38 y 38 ter de la Ley 18.933, en Causa rol No 522 - 2009 de la Corte de Apelaciones DE CONCEPCIÓn (2010): Tribunal Constitucional chileno, Rol No 1535, 28 de enero de 2010, c. 17, 20.

86 Golder v. UNITED KINGDOM. Tribunal Europeo de Derechos Humanos. Sentencia de 21 de febrero de 1975, párr. 38.

87 Ashingdane v. UNITED KINGDom, Tribunal Europeo de Derechos Humanos, Sentencia del 28 de mayo de 1985, párr. 57. Más recientemente: Z Y OTROS v. UNITED KINGDOM, Tribunal Europeo de Derechos Humanos, Sentencia de 10 de mayo de 2001, párr. 93.

88 Medina (2016) p. 250. 
ejercicio del derecho en la medida que pueda predicarse razonabilidad o proporcionalidad de la medida ${ }^{89}$. Así, una de las discusiones jurisprudenciales más recurrentes en el Tribunal Constitucional se ha referido a casos donde la ley exige el pago de una proporción de la multa o sanción impuesta por la Administración (la fórmula del solve et repete) con resultados diversos dependiendo principalmente de la institución que cursa la multa así como de si la exigencia o barrera impuesta es proporcional o no ${ }^{90}$.

El segundo fundamento de la relevancia de la justicia civil tiene que ver con las funciones que esta debe cumplir para la mantención y fortalecimiento del Estado de Derecho. Asumiendo se trata de una cuestión de grado $^{91}$, de acuerdo a Raz entre otros principios básicos como que las leyes deben prospectivas, públicas, y claras, este implica que los tribunales deben ser fácilmente accesibles ${ }^{92}$.

La justicia civil tiene un rol central en varios de los elementos que componen un Estado de Derecho, sobre todo, siguiendo a Waldron, si se pone el énfasis en la importancia en su dimensión formal o procedimental ${ }^{93}$. Su relevancia no solo se ve en el fortalecimiento de un marco jurídico claro para guiar la conducta de los miembros de la sociedad, sino también en la posibilidad de acceder a la justicia. Los derechos son de poco valor si no se tiene la oportunidad de hacerlos efectivos ${ }^{94}$. En este sentido, el valor de la justicia civil no solo se encuentra en la adjudicación sino en la existencia del proceso judicial mismo. De esta manera, mediante la provisión de un proceso público para la resolución de disputas de manera pacífica, se da sustento a la estabilidad social y al crecimiento económico, en tanto los acuerdos y la vida en sociedad se hacen posibles solo cuando los derechos y responsabilidades poseen un marco claro y posible de hacerlos efectivos ${ }^{95}$.

El Estado de Derecho requiere, entonces, no solo que exista un sistema jurídico, sino que también que sus normas, además de proclamadas, de público conocimiento, claras en contenido ${ }^{96}$, sean efectivamente aplicadas. Para ello no basta con la sentencia judicial. Como digo, el proceso civil mismo es relevante en tanto espacio para debatir públicamente sobre los contornos de los derechos que otorga el ordenamiento jurídico. Las actividades propias de la litigación, en casos simples como complejos, obligan a las partes a tratarse como iguales

\footnotetext{
89 Bordalí (2011) p. 330.

90 Bordalí (2011) p. 330-332. Respecto de la jurisprudencia del Tribunal Constitucional, véase: CONTROL DE COnstitucionalidad Respecto del Proyecto de ley Que modifica la Ley No 18.410, Orgánica de la Superintendencia de Electricidad y Combustibles, y el Decreto con Fuerza de Ley No 1, de 1982, de Minería, Ley General de Servicios Eléctricos, con el objeto de Fortalecer el régimen de fiscalización del Sector (1999): Tribunal Constitucional, 27 de mayo de 1999, c. 7. Más recientemente: REQUERIMIENTO DE INAPLICABILIDAD POR inconstitucionalidad presentado por Compañía Eléctrica del Litoral S.A. Respecto del artículo 19 de la Ley No 18.410, en los autos SObre ReCUrso de Reclamación, CARATUlados "Compañía Eléctrica del Litoral S.A. con Superintendencia de Electricidad y Combustibles”, de que conoce la Corte de Apelaciones de Valparaíso, bajo el Rol No 927-2013 (2014): Tribunal Constitucional, 7 de agosto de 2014, c. 5-8.

91 McCorquodale (2010), p. 29.

2 RAZ (1979) pp. 215-219.

93 WaLdRON (2010) pp. 9-11.

94 ZIFCAK (2005) p. 36.

95 Genn (2010) p. 3. En el ámbito internacional véase: ZangL (2008) pp. 828-830.

96 Carothers (1998) p. 96. La traducción es mía.
} 
y a intercambiar información respecto de la cual un tercero imparcial será el encargado de dirimir una controversia de relevancia jurídica. El proceso judicial se presenta así como una manera de modificar normas de conducta mediante participación popular y prácticas igualitarias que permiten limitar y controlar tanto el poder público como privado ${ }^{97}$.

La idea de que las normas sean accesibles es que las implicancias legales de las acciones futuras de los individuos son previsibles y conocidas por ellos ${ }^{98}$. Este ideal de certeza se requiere tanto respecto del derecho sustantivo como a nivel de normas del procedimiento ${ }^{99}$.

El Estado de Derecho requiere, entonces, no solo que exista un sistema jurídico, sino que también que sus normas, además de proclamadas, sean efectivamente aplicadas en la práctica. Sin embargo, el derecho en los libros puede diferir del derecho en la práctica si hay un inadecuado acceso a la maquinaria judicial que pueden tener las partes, o porque los tribunales están congestionados, porque los procedimientos son lentos e ineficientes, o porque la respuesta o sanciones que brinda el sistema son inadecuadas o difícilmente ejecutables. Esto es lo a que Attiyah y Summers llaman una "baja formalidad de aplicación" del derecho ${ }^{100}$.

Pero la importancia de la justicia civil no está solamente en la adjudicación sino también en la existencia y disponibilidad de un mecanismo al cual recurrir para hacer efectivos los derechos. Así, cuando las personas, por los factores que sean, están menos dispuestas a cumplir con las normas sin algún tipo de presión de parte de los tribunales, habrá por lo tanto menor observancia del derecho. En consecuencia, las disputas tenderán a resolverse fuera de las cortes y menos con recurso a este. Mientras menor efecto tengan las normas legales en la resolución de disputas, menor formalidad estará logrando el sistema legal. ${ }^{101}$

Los riesgos están en la pérdida de legitimidad del sistema. Esta, de acuerdo a Habermas, se basa en tres pilares: derecho a iguales libertades (concepción de reciprocidad), derechos de membrecía (no pueden obligar al ciudadano a ser miembro pero tampoco privarle esa posibilidad), y la existencia de remedios o garantías para quienes han visto sus derechos vulnerados ${ }^{102}$. Es justamente esta última dimensión la que se encuentra en un grave riesgo si se sigue concibiendo la justicia civil sin considerar las necesidades legales en estas materias de una ciudadanía cada vez más empoderada. Una justicia civil que no tenga en consideración la situación de las necesidades legales insatisfechas de la población ni sea capaz de re estructurarse con miras a ampliar su alcance, solo llevará a una mayor pérdida de legitimidad de parte nuestra ciudadanía.

Ninguna de las dos dimensiones hoy en día se refleja en nuestra propia justicia civil. Por una parte, los hallazgos de este estudio empírico confirman, al menos para la jurisdicción de la Corte de Apelaciones de Santiago, que las personas naturales utilizan en una proporción ínfima a la justicia para resolver sus necesidades legales de naturaleza civil. Ello

\footnotetext{
97 RESNIK (2014) p. 10.

98 Kinley (2005) p. 100.

99 SCHÖnSteiner (2011) pp. 119-120.

100 Attiyah y Summers (1987) p. 187.

101 Attiyah y Summers (1987) p. 188.

102 Habermas (1996) p. 122.
} 
se refuerza aún más si se toma en consideración los datos de la Encuesta Nacional de Necesidades Jurídicas y Acceso a Justicia, que da cuenta de que este tipo de asuntos es relevante entre la población ${ }^{103}$, y que la mayoría de quienes buscaron una vía para satisfacer estas necesidades no lo hicieron recurriendo al sistema de justicia formal ${ }^{104}$. Por el contrario, las personas naturales cuando ocupan un rol ante el sistema de justicia civil es como demandados, aunque en su mayoría ni siquiera comparecen porque no son notificados. Por el otro lado, la homogeneidad del ingreso civil en la cobranza, sumado a la verificación de la hipótesis de que los principales usuarios son fundamentalmente grandes empresas ligadas al sector financiero, dan cuenta de que la proporción de verdaderos conflictos de relevancia jurídica, para todo tipo de usuarios, es ínfima. En consecuencia, la provisión de estándares de conducta previsibles para los diversos actores de la sociedad, esencial para el correcto funcionamiento del Estado de Derecho, en fin, para el cumplimiento del rol público de la justicia civil, es sumamente deficiente. Con razón Jorge Correa, Carlos Peña, y Juan Enrique Vargas, determinan que la justicia civil chilena bajo su estándar de funcionamiento actual, se comporta más bien como un bien privado cuyos beneficios son internalizados predominantemente por las partes, y particularmente por los demandantes. Las externalidades positivas, por otro lado, serían muy menores ${ }^{105}$.

Los autores nacionales arriba citados abogan, ante la ineficiencia de la justicia civil, más bien por el uso de medios alternativos al proceso judicial que se basan en la idea de la adjudicación privada. Así, para ellos estos serían mecanismos alternativos como el arbitraje u otros donde predominan los acuerdos, producirían resultados más eficientes en términos de ser producidos a menores costos, especializados y flexibles al tipo de conflicto, más rápidos, acordados, y en general libres de las ataduras de una organización rígida y formal que impondrían factores como la independencia judicial u otras garantías procesales. ${ }^{106} \mathrm{El}$ problema es que, como vemos, ambas soluciones presentadas por estos autores tienen por objeto privatizar o realzar el valor privado del conflicto, equiparando el proceso judicial a cualquier otro mecanismo de resolución. Pareciera que para estos autores dado que la justicia civil no tendría remedio, no se justificaría que el Estado invierta en mejorarla. La respuesta sería, entonces, promover otras formas alternativas y privadas de justicia.

Haciendo eco al diagnóstico, también en nuestro país pareciera que la tendencia común en políticas judiciales del sector civil ha estado enfocado en la extracción de causas desde los tribunales civiles hacia mecanismos privados de resolución de controversias ${ }^{107}$, en la creación de tribunales especializados ${ }^{108}$, así como reenfocando el proceso hacia la obtención de acuerdos más que de decisiones judiciales, o haciendo que sean los litigantes quienes deban pagar por la justicia mediante sistemas de recupero de $\operatorname{costos}^{109}$.

\footnotetext{
103 Ministerio de Justicia (2015) p. 27-30.

104 Ministerio de Justicia (2015) p. 79.

105 Correa et al. (2000) pp. 394-398.

106 Correa et al. (2000) pp. 393-394.

107 Véase, por ejemplo: Gutiérrez (2008) p. 113.

108 Costa (2011) p. 159; Evans y UGalde (2014) p. 26.

109 Mery (2010) pp. 5-6.
} 
Más allá de lo relevante que puede ser incorporar e integrar diversos mecanismos de resolución al sistema de justicia formal, resulta fundamental revalorizar el valor intrínseco del proceso judicial. Tanto la adjudicación como la posibilidad misma de litigar es un factor relevante para sentarse a negociar, sobre todo en un marco normativo claro y con una posibilidad real de hacer efectivos los derechos ${ }^{110}$. Sobre todo, y como vengo señalando, el proceso judicial es central para la satisfacción del derecho acceso a la justicia concebido como un derecho humano y para el adecuado cumplimiento de estándares de Estado de Derecho, siendo ambas las principales funciones que al respecto debería cumplir la justicia civil y motivar una eventual reforma a la justicia civil.

\section{CONCLUSIONES}

La literatura nacional, ya ha criticado el actual procedimiento civil por su carácter formalista, escrito, y lento. Una serie de estudios también muestran una mala percepción y una serie de asuntos que no llegarían a la justicia civil. Haciendo eco de la literatura del movimiento mundial por el acceso a la justicia, sin embargo, es posible señalar que su estado es peor que el que pensábamos. No solo se trata de una justicia inaccesible sino que, además, hoy en día resulta irrelevante (salvo para la cobranza o declaración de incobrabilidad de deudas de poca monta). Luego, de la comparación entre el funcionamiento actual de la justicia civil con las funciones que debería estar cumpliendo, es que se señala que la justicia civil chilena está en crisis.

Sin embargo, las políticas públicas judiciales a partir del retorno a la democracia no se han enfocado en mejorar el funcionamiento de los tribunales civiles. La estrategia, pareciera ser, por el contrario, extraer asuntos de la competencia civil, la cual es vista como socialmente ineficiente ${ }^{111}$. En este sentido, basta ver el presupuesto invertido en la justicia penal, en las reformas en materias de familia y laboral, en la creación de tribunales administrativos especializados, o en la proliferación de sistemas alternativos de resolución de conflicto. Por el contrario, los esfuerzos en lo civil no han pasado de proyectos de código y en reformas legislativas menores y que de todas maneras no buscan modificar el modelo de proceso civil imperante en nuestro país ${ }^{112}$.

Sin embargo, antes su reforma, debemos cuestionarnos por qué el Estado debería invertir en una reforma a la justicia civil, dadas las condiciones de funcionamiento y de quienes son actualmente sus principales usuarios. Si creemos que el acceso a la justicia civil es un derecho humano y su correcto funcionamiento debe servir para fortalecer y mantener el Estado de Derecho, se hace necesario revalorizar su carácter público. La justicia civil debe ser un espacio abierto donde ambas partes puedan llevar sus casos y luego participar de manera efectiva, colocándose como iguales ante un tercero imparcial obligado constitucionalmente a mantener ciertas condiciones mínimas para el debate, donde sea posible

\footnotetext{
110 GenN (2010) p. 80.

111 Correa et al. (2000) pp. 393-394.

112 Por ejemplo, la Ley No 20.886, también denominada Ley de Tramitación Electrónica. Esta no cambia el modelo de litigación civil sino que busca mejorar el intercambio de documentos usando medios tecnológicos.
} 
participar del debate público dando claridad y predictibilidad a las normas que componen el ordenamiento jurídico, permitir los acuerdos, reafirmar estándares de conducta futuros para ciudadanos, empresas, agencias públicas, así como limitar y controlar tanto el poder público como privado. Partiendo de la base de la amplia brecha entre el funcionamiento actual el ideal de la justicia civil, el sentido de urgencia se hace bastante más evidente. Los riesgos al final del día están en la pérdida de legitimidad del sistema que demanda la existencia de remedios o garantías para quienes han visto sus derechos vulnerados.

\section{BIBLIOGRAFÍA CITADA}

Agencia de los Derechos Fundamentales de la Unión Europea (2011): Access to Justice in Europe: an Overview of Challenges and Opportunities (Luxemburgo, Consejo de Europa).

Agencia de los Derechos Fundamentales de la Unión Europea (2016): Handbook on European Law Relating to Access to Justice (Luxemburgo, Consejo de Europa).

Asamblea General de las Naciones Unidas (2012): La extrema pobreza y los derechos humanos. Informe de la Relatora Especial sobre la extrema pobreza y los derechos humanos (Naciones Unidas, A/67/278).

Atтiyah, P.S. y Summers, Robert S. (1987): Form and Substance in Anglo-American Law. A Comparative Study of Legal Reasoning, Legal Theory, and Legal Institutions (Estados Unido, Oxford University Press).

Barros Lezaeta, Luis (1997): Opiniones de los Sectores Populares Urbanos En Torno a la Justicia (Santiago, Centro de Desarrollo Jurídico Judicial, Corporación de Promoción Universitaria).

Bates, Luis (1992): “Acceso a la Justicia y las Personas de Escasos Recursos”, Cuadernos de Análisis Jurídicos, No 22, pp. 161-166.

Bordalí, Andrés (2009): “Organización Judicial en el Derecho Chileno: Un Poder Fragmentado", Revista Chilena de Derecho, vol. 36 No 2: pp. 215-244.

Bordalí, Andrés (2011): "Análisis Crítico de la Jurisprudencia del Tribunal Constitucional sobre el Derecho a la Tutela Judicial”, Revista Chilena de Derecho, vol. 38 No 2: pp. 311-337.

Caplan, Bryan, y Stringham, Edward P. (2008): "Privatizing the Adjudication of Disputes", Theoretical Inquiries in Law, vol. 9: pp. 503-528.

Cappelletti, Mauro y Garth, Bryant (1996): El Acceso a la Justicia, La Tendencia en el Movimiento Mundial Para Hacer Efectivos los Derechos (Trad. Mónica Miranda, México, Fondo de Cultura Económica).

Caroca, Alex (1997): Derechos Humanos y Derecho Civil: Una Perspectiva Procesal, Centro de Desarrollo Jurídico Judicial (Santiago, Corporación de Promoción Universitaria).

Carothers, Thomas (1998): "The Rule of Law Revival”, Foreign Affairs, vol. 77 No 2: pp. 95-106.

Centro de Estudios de Justicia de las Américas (2011): Estudio de Análisis de Trayectoria de las Causas Civiles en los Tribunales Civiles de Santiago. Informe Final (Santiago, Ministerio de Justicia). 
Cerda, Carlos (1997): “Organicidad y funcionalidad de menor y mínima cuantías en el Derecho chileno”, Cuadernos de Análisis Jurídico, Serie Seminarios No 33: pp. 355-378.

Colombo, Juan (1991): La Jurisdicción en el Derecho Chileno. Un Aporte al Estudio del Conflicto y sus Formas de Solución (Santiago, Editorial Jurídica de Chile).

Correa Sutil, Jorge y Barros Lezaeta, Luis (1993): Justicia y Marginalidad, Percepción de los Pobres (Santiago, Corporación de Promoción Universitaria).

Correa Sutil, Jorge y Jiménez, María Angélica (1997): "Sistema Judicial y Pobreza, Estudio sobre el Acceso a la Justicia en Argentina, Chile, Perú y Venezuela", Cuadernos de Análisis Jurídico, No 35.

Correa, Jorge, et al. (1999): "Poder Judicial y Mercado", Informes de Investigación del Centro de Investigación Facultad de Derecho, № 2, Año 1.

Correa, Jorge et al. (2000): “¿Es la Justicia un Bien Público?”, Revista Perspectivas, vol. 3, No 2: pp. 389-409.

Costa, Ezio (2011): "Los Tribunales Administrativos Especiales en Chile", Revista de Derecho, vol. 27, No 1, pp. 151-167.

Couture, Eduardo (1950): “The Nature of Judicial Process", Tulane Law Review, vol. XXV, No 1: pp. 1-28.

Couture, Eduardo J. (2014): Fundamentos del Derecho Procesal Civil (Argentina, B de F, Cuarta edición).

Croley, Steven P. (2017): Civil Justice Reconsidered. Toward a Less Costly, More Accessible Litigation System (Ney York, New York University Press).

DAMAšKA, Mirjan (1986): The Faces of Justice and State Authority (Estados Unidos, Yale University Press).

Dakolias, María (1995): "A Strategy for Judicial Reform: The Experience in Latin America", Virginia Journal of International Law, vol. 36: pp. 167-231.

Domínguez, Juan Pablo (2007): "Reflexiones en torno a la Propuesta de Reforma al Procedimiento Civil Chileno: III. Principios Procesales Relativos al procedimiento", Revista Chilena de Derecho, vol. 34, No 3: pp. 595-596.

Dworkin, Ronald (1977): Taking Rights Seriously (Cambridge, Harvard University Press).

EMG CONSUltores (2012): Estudio de Estimación de Ingreso de Causas para el sistema de Justicia Civil bajo el Actual Régimen de Funcionamiento (Santiago, Ministerio de Justicia).

Evans, Eugenio y Ugalde, Francisca (2014): "Algunas Jurisdicciones Especializadas. El Caso del Panel de Expertos Eléctrico y su Importancia para el Debido Juzgamiento", en: Panel de Expertos de la ley General de Servicios Eléctricos (ed.), Resolución de Discrepancias en el Sector Eléctrico Chileno: Reflexiones a 10 años de la Creación del Panel de Expertos (Santiago, Pontificia Universidad Católica de Chile) pp. 9-30.

Galanter, Marc (2006): "A World Without Trials", Journal of Dispute Resolution, No 1: pp. 7-33.

García, Gonzalo y Contreras, Pablo (2013): "El Derecho a la Tutela Judicial y al Debido Proceso en la Jurisprudencia”, Estudios Constitucionales, Año 11, No 2: pp. 229-282.

García, José Francisco y Leturia, Francisco Javier (2006): "Justicia Civil: Diagnóstico, Evidencia Empírica, y Lineamientos para una Reforma", Revista Chilena de Derecho, vol. 33, No 2: pp. 345-384. 
GonzÁlez, Jesús (1984): El Derecho a la Tutela Jurisdiccional (Segunda Edición, Madrid, Editorial Civitas).

Genn, Hazel (2010): Judging Civil Justice (Cambridge, Cambridge University Press).

Gutiérrez, María José (2008): “La Mediación en Salud y el Acceso a la Justicia”, Revista de Derecho del Consejo de Defensa del Estado, No 20, pp. 111-137.

Habermas, Jürgen (1996): Between Facts and Norms, Contributions to a Discourse Theory of Law and Democracy (Trad. William Rehg Cambridge, Cambridge The MIT Press).

Instituto Interamericano de Derechos Humanos et al. (2010): Manual Autoformativo sobre Acceso a la Justicia y Derechos Humanos en Chile (Costa Rica, Instituto Interamericano de Derechos Humanos).

Kagan, Robert. A (2003): Adversarial Legalism. The American Way of Law (Cambridge, Harvard University Press).

Kinley, David (2005): "The Universalizing of Human Rights and Economic Globalization. What Roles for the Rule of Law?", en ZIFCAK, Spencer (ed.), Globalisation and the Rule of Law (Gran Bretaña, Routledge) pp. 96-118.

Leturia, Francisco Javier (2006): “Ampliación del Ámbito del Arbitraje: Una Solución Estructural para Algunas de los Problemas de la Justicia Civil”, en Silva, José Pedro et al. (ed.), Justicia Civil y Comercial: Una Reforma Pendiente. Bases para el Diseño de la Reforma Procesal Civil (Santiago, Libertad y Desarrollo, Pontificia Universidad Católica de Chile) pp. 263-312.

Mery, Rafael (2006): "Una Aproximación Teórica y Empírica a la Litigación Civil en Chile”, en Silva, José Pedro et al., Justicia Civil y Comercial: Una Reforma Pendiente. Bases para el Diseño de la Reforma Procesal Civil (Santiago, Fundación Libertad y Desarrollo, Pontificia Universidad Católica de Chile) pp. 83-136.

Mery, Rafael (2010): “Tasas Judiciales: Una Alternativa Para la Justicia Civil”, Latin American and Caribbean Law and Economics Association (ALACDE) Annual Papers.

Marinoni, Luiz et al. (2010): Fundamentos del proceso civil. Hacia una teoría de la adjudicación (Santiago, Abeledo Perrot, LegalPublishing).

McCorquodale, Robert (2010): "Business, Rule of Law and Human Rights", en McCorquodale, Robert (ed.) The Rule of Law in International and Comparative Context (Londres, British Institute of International and Comparative Law); pp. 27-47.

Medina, Cecilia (2016): The American Convention on Human Rights. Crucial Rights and Their Theory and Practice (Reino Unido, Intersentia).

Merryman, John Henry y Pérez-Perdomo, Rogelio (2014): La Tradición Juridica RomanoCanónica (Trad. Eduardo L. Suárez y José María Ímaz, México, Fondo de Cultura Económica, Tercera Edición).

Michalik, Paul (1999): "Justice in Crisis: England and Wales", en Zuckerman, Adrian A. $S$ (edit.), Civil Justice in Crisis. Comparative Perspectives of Civil Procedure (New York, Oxford University Press) pp. 117-165.

Ministerio de Justicia (2012): Proyecto de ley de nuevo Código Procesal Civil (Santiago, Ministerio de Justicia).

Ministerio de Justicia (2015): Informe Final, Encuesta Nacional de Necesidades Jurídicas y Acceso a la Justicia (Santiago, Gfk Adimark). 
Montero Aroca, Juan (2016): El Proceso Civil, Los Procesos Ordinarios de Declaración y de Ejecución (Valencia, Tirant lo Blanch, Segunda Edición).

Moyer, Thomas J. y STEWART, Emily (2003): "Mediation as a Catalyst for Judicial Reform in Latin America”, Ohio State Journal on Dispute Resolution, vol. 18, No 3: pp. 619-668.

Nuñez, Raúl (2005): "Crónica sobre la Reforma del sistema Procesal Civil Chileno (Fundamentos, Historia y Principios)", Revista Estudios de la Justicia, No 6: pp. 175-189.

Otero, Miguel (2000): Derecho procesal civil. Modificaciones a la Legislación 1988-2000 (Santiago, Editorial Jurídica de Chile).

Palomo, Diego (2005): Proceso Civil Oral: ¿Qué Modelo de Juez Requiere?, Revista de Derecho, vol. XVIII, No 1: pp. 171-197.

Pastor, Santos (2006): Análisis Económico de la Justicia y Reforma Judicial (Valencia, Tirant lo Blanch).

PNUD (2005): Manual de Politicas Públicas para el Acceso a la Justicia. América Latina y el Caribe (Buenos Aires, Ediciones del Instituto).

Pontificia Universidad Católica de Valparaíso (2012): Informe Final. Diseño de un Modelo de Oficial de Ejecución (Valparaíso, Ministerio de Justicia).

Raz, Joseph (1979): The Authority of Law: Essays on Law and Morality (Oxford, Clarendon Press).

Raz, Joseph (1995): Ethics in the Public Domain. Essays in the Morality of Law and Politics (Oxford, Clarendon Press).

Resnik, Judith (2014): "Reinventing Courts as Democratic Institutions", Daedalus, vol. 143, No 3, pp. 9-27.

Riego, Cristián y Lillo, Ricardo (2015): “¿Qué se ha dicho sobre el funcionamiento de la Justicia Civil en Chile? Aportes para la Reforma," Revista Chilena de Derecho Privado, No 25 (Diciembre de 2015): pp. 9-54.

Rhodes, Deborah L. (2004): "Access to Justice" (New York, Oxford University Press).

SchÖnsteIner, Judith (2011): Structural Impartiality and The Inter-American Court of Human Rights: Managing The Influence Of Actors, Institutions And Procedures (University of Essex, British Library).

Trebilcock, Michael et al. (ed.) (2012): Middle Income Access to Justice (Toronto, University of Toronto Press).

Vanderschueren, Franz y Oviedo, Enrique (ed.) (1995): Acceso de los Pobres a la Justicia (Santiago, Ediciones Sur).

Vargas, Juan Enrique (2001): "Problemas de los Sistemas Alternos de Resolución de Conflictos como Alternativa de Política Pública en el Sector Judicial”, Revista Sistemas Judiciales, No 2: pp. 1-11.

VArgas, Juan Enrique et al. (2001): "El Rol del Estado y el Mercado en la Justicia”, Cuadernos de Análisis Jurídico, Serie Seminarios No 42.

VArgas, Macarena (2011): "Reflexiones en Torno a la Figura del Oficial de Ejecución”, en Leturia, Francisco Javier (ed.), Justicia Civil y Comercial: Una Reforma ¿Cercana? (Santiago, Ediciones LYD) pp. 471-488.

Waldron, Jeremy (2010): "The Rule of Law and the Importance of Procedure", New York University Public Law and Legal Theory Working Papers, No 234. 
Wenstein, Ian (2016): "Access to Civil Justice in America: What Do We Know?", en Estreicher, Samuel y Radice, Joy (ed.), Beyond Elite Law: Access to Civil Justice in America (New York, Cambridge University Press) pp. 3-20.

ZANDER, Michael (1995): "Why Lord Woolf's Proposed Reforms of Civil Litigation Should be Rejected”, en Zuckerman, Adrian A. S y Cranston, Roos (ed.), Reform of Civil Procedure. Essays on "Access to Justice" (Oxford, Clarendon Press) pp. 79-96.

ZaNGL Bernhard (2008): "Judicialization Matters! A Comparison of Dispute Settlement under GATT and the WTO”, International Studies Quarterly, vol. 52, No 4: pp. 825-854.

ZIFCAK, Spencer (2005): "Globalizing the Rule of Law. Rethinking Values and Reforming Institutions”, en ZIFCAK, Spencer (ed.), Globalisation and the Rule of Law (Gran Bretaña, Routledge): pp. 32-64.

Zuckerman, Adrian A. S (ed.) (1999): Civil Justice in Crisis. Comparative Perspectives of Civil Procedure (New York, Oxford University Press).

\section{JURISPRUDENCIA CITADA}

Airey V. IRLANDA. Tribunal Europeo de Derechos Humanos. Sentencia del 9 de octubre de 1979.

Ashingdane v. United KInGDom, Tribunal Europeo de Derechos Humanos, Sentencia del 28 de mayo de 1985.

GoldeR v. UNITED KINGDOM. Tribunal Europeo de Derechos Humanos. Sentencia de 21 de febrero de 1975.

Claude Reyes y otros vs. Chile. Corte Interamericana de Derechos Humanos. Sentencia del 19 de septiembre de 2006.

Control de Constitucionalidad Respecto del proyecto de ley QUe modifica la Ley No 18.410, Orgánica de la Superintendencia de Electricidad y Combustibles, y el Decreto con Fuerza de Ley No 1, de 1982, de Minería, Ley General de Servicios ElécTRICOS, CON EL OBJETO DE FORTALECER EL RÉGIMEN DE FISCALIZACIÓN DEL SECTOR (1999): Tribunal Constitucional, 27 de mayo de 1999.

FERNÁNDEZ ORTEGA Y OtRos vs. MÉXICO. Corte Interamericana de Derechos Humanos. Sentencia del 30 de agosto de 2010.

MCVICAR V. UNITED KINGDOM. Tribunal Europeo de Derechos Humanos. Sentencia del 7 de Mayo de 2002.

P,C AND $S$ v. UNITED KINGDOM. Tribunal Europeo de Derechos Humanos. Sentencia del 16 de Julio de 2002.

REQUERIMIENTO DE INAPLICABILIDAD POR INCONSTITUCIONALIDAD DE EDUARDO HEMMELMANN Troncoso, respecto de los artículos 38 y 38 ter de la Ley 18.933, en CAUSA rol No 522 - 2009 de la Corte de Apelaciones de Concepción (2010): Tribunal Constitucional chileno, Rol No 1535, 28 de enero de 2010.

REQUERIMIENTO DE INAPLICABILIDAD POR INCONSTITUCIONALIDAD PRESENTADO POR COMPANÍA Eléctrica del Litoral S.A. Respecto del artículo 19 de la Ley No 18.410, en los autos sobre recurso de reclamación, caratulados "Compañía Eléctrica del LitoRal S.A. CON Superintendencia de Electricidad y Combustibles”, De QUe CONOCe 
la Corte de Apelaciones de Valparaíso, bajo el Rol No 927-2013 (2014): Tribunal Constitucional, 7 de agosto de 2014. STEEL \& MORRIS v. UNITED KINGDOM, Tribunal Europeo de Derechos Humanos. Sentencia del 15 de Febrero de 2005.

Julius Kloiber SChlachthof GMBH and Others v. Austria. Tribunal Europeo de Derechos Humanos. Sentencia del 4 de abril de 2013.

$Z_{\text {y }}$ OtRos v. UNITED KINGDOM, Tribunal Europeo de Derechos Humanos, Sentencia de 10 de mayo de 2001. 